\title{
Stealth Trading by Corporate Insiders ${ }^{*}$
}

\author{
Olga Lebedeva ${ }^{\mathrm{a}}$
}

\author{
Ernst Maug ${ }^{\mathrm{b}}$
}

November 19, 2009

\begin{abstract}
This paper analyzes stealth trading by corporate insiders in US equity markets. Stealth trading is the practice to break up trades into sequences of smaller trades. We find that stealth trading is pervasive and distinguish two explanations. The first argues that insiders break up trades in order to conceal private information about the fundamental value of the stock, whereas the second holds that insiders act like discretionary liquidity traders who want to reduce the temporary price impact from trading large stakes. We find some, but inconsistent evidence for information-based explanations, but strong and unambiguous evidence for liquidity-based explanations. These conclusions hold across subsamples for transactions before and after the Sarbanes-Oxley act and for NASDAQ as well as NYSE stocks.
\end{abstract}

JEL classifications: G14, G34, G38

Keywords: Stealth Trading, Insider Trading, Sarbanes-Oxley

We thank Eric Theissen and Bohui Zhang for discussions and advice at an earlier stage of this paper. We thank the collaborative research centers SFB 504 "Rationality Concepts, Decision Making and Economic Modeling" and TR/SFB 15 "Governance and the Efficiency of Economic Systems" at the University of Mannheim and the Rudolf von Bennigsen-Foerder foundation for financial support.

a University of Mannheim, 68131 Mannheim, Germany. E-mail: lebedeva@corporate-finance-mannheim.de. Tel: +496211812278.

b University of Mannheim, 68131 Mannheim, Germany. E-mail: maug@corporate-finance-mannheim.de. Tel: +496211811952.

c University of Mannheim, 68131 Mannheim, Germany. E-mail: schneider@corporate-finance-mannheim.de. Tel: +49621 1811949 . 


\section{Introduction}

Between May 24 and May 26, 2005, Eric Schmidt, the CEO of Google, sold shares worth $\$ 29.3$ million of Google stock and split this trade into 1,744 transactions. ${ }^{1}$ In this paper, we investigate such stealth trades by corporate insiders, where stealth trading is the strategy to break up trades into sequences of smaller trades (Barclay and Warner, 1993). While the example of Eric Schmidt's trades is extreme, it is common for insiders to break up their trades into two to ten transactions. However, some orders, even large ones, are not broken up at all. There are two explanations for stealth trading. The first explanation is that traders possess private information about the fundamental value of shares and may therefore want to conceal their trades in order to hide this information. This hypothesis was put forward by Barclay and Warner (1993), who refer to Kyle (1985) as a theoretical basis for their hypothesis. ${ }^{2}$ The second explanation is that traders act as discretionary liquidity traders who do not possess private information, but try to optimally use market liquidity by placing their orders in markets and during trading hours when liquidity is large and when the price impact of their trades is small. ${ }^{3}$ For both hypotheses it is immaterial to what extent insiders make use of intermediaries to break up their orders as long as they exercise control over the decision whether their orders are split or not.

A major difficulty with analyzing these explanations is that transaction databases do not track the identity of investors who buy and sell shares. Standard databases can therefore not reveal sequences of stealth trades and all evidence on stealth trading is therefore necessarily

1 In all likelihood Schmidt split his trades with the help of an intermediary who offers electronic order processing. An article in Securities Industry News dated September 18, 2006, reports that JP Morgan Chase's electronic client solutions unit offers two new liquidity-seeking algorithms that scan NASDAQ and seven trading platforms to provide ,hidden-liquidity trading.“ A more recent article (Forbes, January 12, 2009) describes order splitting of CS First Boston's „Advanced Execution System,“ for which „the average institutional trade is now only 233 shares".

2 In Kyle (1985) the insider is a monopolist for long-lived information. Holden and Subrahmanyam (1992) show that his argument may not carry over to a situation where multiple insiders possess the same information. They will then compete for the use of this information and trade in a shorter period of time, which in our context means that they engage less in stealth trading. Huddart, Hughes, and Levine (2001) adapt Kyle's model to a context where insiders have to disclose their trades, but in their setting insiders can only place one order before they disclose their trade, which precludes stealth trading.

3 The notion of discretionary liquidity trading was developed by Admati and Pfleiderer (1988). Theirs is a model of one exchange, but the argument extends easily to a setting where liquidity traders can trade simultaneously on multiple platforms. 
indirect. ${ }^{4}$ As a result, the literature on stealth trading follows the pioneering work of Barclay and Warner (1993) and provides evidence for stealth trading indirectly by analyzing the informativeness of trades of different sizes. They argue that small trades can be ignored. Large trades reveal more of the trader's information. They have therefore a larger price impact, which makes them less profitable. Accordingly, medium-size trades provide an optimal tradeoff between the desired scale of the transaction and the objective to conceal information and are therefore the strategy of choice. The empirical method then infers stealth trading by demonstrating that medium-size trades have a larger permanent impact on prices compared to small and large trades. This method has been applied successfully to analyze stealth trading in targets of tender offers or in stocks with large price movements relative to the market index. ${ }^{5}$ The main limitation of this method is that the research design has to focus on stocks or events where significant firm-specific information is revealed, and that it is therefore biased towards information-based explanations. These papers also restrict their samples to a small number of stocks or options, to a short sample period, and to securities subject to abnormally large price changes.

In this paper, we provide direct evidence on stealth trading by investigating a class of traders for whom we can directly identify their trades: the officers and directors of companies. We investigate how much and under what circumstances company insiders split their trades by looking at sequences of repeated trades in the same direction. ${ }^{6}$ Company insiders are a particularly suitable laboratory to investigate stealth trading. First, we can observe stealth trading directly. Second, we do not need to restrict the sample to firms that were subject to particular events or to particular price movements. We include all listed U.S. corporations over a sample period of 11 years from 1996 to 2006 for which we can obtain data, and our final sample covers 1.855 million individual transactions. Third, the issue of stealth trading is especially im-

4 Chakravarty (2001) identifies the class of traders (institutional or individual) from the account type in the clearing records, but his data cannot identify individual traders. Keim and Madhavan (1995) provide some evidence on order break-up for trades of 21 institutional investors, but note that aggregation of orders in their data does not allow them to fully identify the number of trades used to fill one order. Alexander and Peterson (2007) argue that clustering of trades at sizes of 500, 1000, and 5000 shares is indicative of stealth trading.

5 Barclay and Warner (1993), Chakravarty (2001), and Anand and Chakravarty (2007).

6 We use the term "insider trading," "insiders," and related formulations exclusively in order to refer to legal trades as reported to the regulator by persons who are classified as insiders by applicable insider trading laws. The term "directors' dealings" as used in the UK is too narrow for our purposes, as it does not include insiders who are not directors or officers of the company. 
portant for company insiders, because they supposedly gain their information by virtue of their relationship with the company. Their trading behavior is therefore of independent interest and the subject of a separate and large literature. We investigate whether stealth trading allows insiders to gain additional advantages from their informational position through stealth trading. ${ }^{7}$ In 2002, about the middle of our sample period, the Sarbanes-Oxley act (SOX) tightened insider trading rules and we are also interested in the extent to which this change in regulation affects stealth trading.

Our first step is to define stealth trading more precisely and to show that stealth trading by corporate insiders is pervasive and that sequences of trades in the same direction are the norm. In a second step, we formulate two groups of hypotheses based on the fact that the stock price change caused by a trade consists of two components. First, a permanent component, reflecting the new fundamental information revealed by the trade. Second, a transitory component, which arises for microstructure reasons such as compensation to those who provide liquidity and who take on inventory risk. Since both components of price impact increase with transaction size, an insider can increase her trading profit by splitting her transactions into smaller trades and spread them over time, independently of whether she trades on private information or for liquidity reasons.

Information-based explanations focus on the first, permanent component of stock price changes and assume that insiders are informed traders and that stealth trading allows them to use their private information more profitably. Barclay and Warner (1993) argue that informed traders have an incentive to spread their information over time. If private information is longlived, then they have an incentive to spread it over the entire period before this information becomes public. We find evidence for some information-based hypotheses but not for others. We adapt the information-hierarchy hypothesis known from the insider trading literature and argue that insiders with better access to private information should engage more in stealth trading. Our findings contradict this hypothesis if we pool observations across the whole sample, but the evidence by officers and directors supports the information-hierarchy argument

7 This is a large literature to which we cannot do any justice in this article. Bainbridge (1999) is a good survey. The earliest contributions we could trace are Rogoff (1964), Lorie and Niederhoffer (1968), Pratt and DeVere (1970), Scholes (1972), Jaffe (1974), and Finnerty (1976). Recent contributions include Fidrmuc, Goergen, and Renneboog (2006), Marin (2008), and Fernandes and Ferreira (2009). 
for the period before the Sarbanes-Oxley act. Microstructure-based measures of asymmetric information and accounting-based measures of firms' opacity and disclosure quality have mostly only marginal explanatory power. Finally, the disclosure of stealth trades does not generate larger announcement returns than the disclosure of non-stealth trades.

The second group of explanations are liquidity-based explanations, which consider the temporary component of stock price changes and view insiders simply as large traders who use stealth trading in order to reduce the price impact of their trades. In a finitely liquid market, large trades will have an impact on market prices even if trades are not caused by private information. Casual observations suggest that computerized trading has made this source of trade fragmentation more important in recent years, and that brokers and banks offer their clients services to route their orders systematically to exchanges and trading platforms to exploit changes in liquidity. From this perspective, insiders may act as discretionary liquidity traders. If liquidity motives dominate, then insiders should use stealth trading in illiquid markets, if more insiders trade simultaneously in the same direction, and whenever they are on the short side of the market so that trading becomes more difficult. We consistently find supporting evidence for all hypotheses based on the notion that stealth trading tries to minimize price impact and to exploit market liquidity. We compare the explanatory power of information-based explanations and liquidity-based explanations of stealth trading and find that liquidity-based explanations have consistently more explanatory power, whereas the support for informationbased explanations is weaker and less consistent. ${ }^{8}$

We investigate stealth trading in more detail by looking at transactions before and after the passage of the Sarbanes-Oxley act. The Sarbanes-Oxley-Act (SOX) reduced the time insiders have to disclose their trades from up to forty calendar days to only two business days. During our sample period from 1996 to 2006, we observe a trend towards less stealth trading if we measure it by the volume of stealth trades compared to non-stealth trades, but an increase if we measure it by the number of trades. Insiders adapted to the regulatory change by

8 The trades by Eric Schmidt reported at the beginning of the Introduction illustrate this point. He divested Google A-shares that he acquired through recent stock option exercises and the week where he conducted the transactions had the third-highest trading volume of any week in the entire year 2005, which is consistent with timing the liquidity of the market. By contrast, an information-based explanation is more difficult to sustain in this case as Google's stock rose by $60 \%$ by the end of the year 2005 and dropped below the price at which Schmidt sold his shares only in the wake of the financial crisis more than four years later. 
executing smaller stealth trades, by trading more frequently, and by concentrating stealth trades into shorter time intervals. Most other changes that differ in the period before and after the Sarbanes-Oxley act seem to be related to a steady increase in market liquidity, but unrelated to the change in regulation itself. In the second half of the sample period where liquidity is higher, liquidity-based explanations become economically less important, although they remain statistically significant.

The argument proceeds as follows. We describe the main features of the relevant institutional framework and the construction of our data set in Section 2. In Section 3, we establish that stealth trading of corporate insiders actually exists. We develop our hypotheses on different aspects of stealth trading and test them in Section 4. In Section 5 we extend the argument and perform several robustness checks. Section 6 concludes.

\section{Institutional framework and data}

\subsection{Institutional framework}

According to Section 16 of the Securities Exchange Act of 1934, all insiders have to disclose their transactions to the SEC. Insiders are direct and indirect beneficial owners of more than ten percent of any class of equity securities and any director or officer of the issuer of equity securities (Section 16(a)(1) of the Securities Exchange Act of 1934, SEC rule 16a-2). Traditionally, insiders had to report their transactions on a monthly basis within 10 days after the end of each calendar month in which the transaction occurred (Form 4), which gave insiders up to forty days to disclose their trades. In 2002, the Sarbanes-Oxley Act (SOX) changed this

practice. Since August 29, 2002, insiders have to report their trades within two business days (SEC rule 16a-3(g)). Small acquisitions that do not exceed $\$ 10,000$ in market value within six months (SEC rule 16a-6) are exempt from these reporting requirements. These small acquisitions are not reported on Form 4 as usual insider transactions but on Form 5, which is due only within 45 days after the issuer's fiscal year end (SEC rule 16a-3(f)).

\subsection{Construction of the data set}

Our data source for insider transactions is the Insider Filing Data Feed (IFDF) provided by Thomson Reuters. IFDF collects information on three forms insiders have to file with the SEC: Form 3 ("Initial Statement of Beneficial Ownership of Securities"), Form 4 ("Statement 
of Changes of Beneficial Ownership of Securities"), and Form 5 (“Annual Statement of Beneficial Ownership of Securities"). We include all open market purchases and sales as well as private transactions between January 1, 1996 and December 31, 2006 with complete data (including CUSIP, transaction date, and disclosure date) on IFDF.

Insert Table 1, Table 2, and Table 3 here

Table 1 provides the details of the construction of our data set. Table 2 provides the definitions of all variables used in our study. We motivate the definitions of our variables alongside the development of our hypotheses below. Table 3 displays some descriptive statistics for the variables in our data set. We extract 2,432,168 transactions for 137,806 insiders from 16,522 firms. $26.7 \%$ of these transactions are purchases and the remaining $73.3 \%$ are sales. We lose about $15 \%$ of the observations because the firm is not listed on CRSP and another $2.7 \%$ because the stock data available on CRSP are insufficient to compute abnormal returns. We also delete all transactions where the number of shares in the transaction (as reported on IFDF) exceeds the number of shares traded on the exchange on the same day (as reported by CRSP); these transactions (about 5\%) are most likely privately negotiated and therefore not of interest for our analysis. We have a small number of cases where insiders trade in different directions on the same day (about 0.7\%) and where the transaction data on IFDF is incomplete (about $0.3 \%$ ). We delete these transactions. We are left with 1,855,068 transactions by 97,205 insiders of 9,563 firms, or $76.3 \%$ of the raw data. Of these $20.9 \%$ are purchases and $79.1 \%$ are sales. For these transactions, we obtain several measures of companies' opacity from Compustat and spreads and other measures of market liquidity from the TAQ database (see Table 2 for details). We lose up to 730,000 observations when calculating opacity measures because of missing information on required items on Compustat. We winsorize all Compustat variables at the first and the $99^{\text {th }}$ percentiles, consistent with the literature on earnings management. ${ }^{9}$ We calculate several liquidity measures from the TAQ data and set variables to missing values if they are outside of their theoretical ranges. ${ }^{10}$ For this reason, the number of

9 See Francis et al (2005) and Cornett et al. (2008).

10 For example, the adverse selection component as the percentage of the effective spread, Lambda, derived by Lin, Sanger and Booth, (1995) has to lie between zero and one. Therefore, we set it to missing if it does not fall into this range. 
transactions with non-missing liquidity measures varies between 844,946 for Gamma and 1,727,517 for QuotedSpread.

\section{Definition, existence, and patterns of stealth trading}

Definition. We regard a transaction as a stealth trade if there exists a subsequent transaction in the same direction and by the same insider before or on the same day where the first transaction is disclosed. The reason for this definition is that stealth trading is relevant only for the period where the information, respectively the trade, has not been disclosed. ${ }^{11}$ Disclosure requirements changed with SOX on August 29, 2002. However, before and after SOX insiders did sometimes not comply with these regulations. We therefore use the actual rather than the mandated disclosure date to identify sequences of stealth trades. We define the maximum length of a stealth trading sequence to be 40 days. If the first trade of a stealth trading sequence is not reported after 40 days, then we consider this sequence to be finished to avoid sequences that stretch over extremely long periods. ${ }^{12}$ We consider alternative definitions of stealth trading as a robustness check below.

\subsection{Existence of stealth trading}

The first step of our analysis is to establish that stealth trading even exists. The evidence in the extant literature is indirect and does not establish a clear-cut criterion that defines stealth trading. We consider the clustering of trades by the same person in the same direction as evidence for stealth trading. Absent stealth trading, insiders' trades should be uncorrelated over time, i.e., if an insider executes purchases with probability $p$ and sales with probability $1-p$, then this unconditional probability should be equal to the conditional probability given that the last transaction was a sale. An analogous argument applies to purchases. We first perform univariate tests to see whether the unconditional probability and the conditional probability of a sale given the direction of the previous transaction are the same. In addition, we perform multivariate tests to control for other factors that may lead insiders to cluster their trades.

11 This is a conservative definition. Huddart, Hughes, and Levine (2001) analyze a model where insiders have to disclose their trades after every trading round and find that this disclosure requirement induces insiders play mixed strategies and to garble the information from disclosures by trading in the opposite direction of their information. Their setup strictly precludes stealth trading, but shows that insiders may possess private information even after they disclose their trade.

12 These 40 days define the upper legal bound for reporting most insider trades before SOX became effective. 


\section{Insert Table 4 here}

Panel A of Table 4 reports the results for the univariate tests. Since we need the sign of the previous transaction, the calculations do not include the first transaction for each person. Table 4 shows that trades cluster. In total, 20.9\% of all transactions are purchases and 79.1\% are sales (see Table 3). Yet, conditional on the previous transaction being a sale (purchase), the next transaction is also a sale (purchase) in $98.7 \%(96.8 \%)$ of all cases. We use a standard Chi-square test and Fisher's exact test to test whether the direction of trades is independent from the direction of previous transactions and reject this hypothesis since the p-values are below $0.01 \%$ in both cases. We repeat the analysis for sub samples of the data where the next transaction occurs within six months (column 2), within 40 days (column 3) and within 2 days (column 4) of the first transaction. The six months restriction is motivated by the short-swing rule, which requires insider to disgorge all profits from trading in the opposite direction (e.g., first buying and then selling) in shares of their own company within six months. The 40-day restriction is motivated by the pre-SOX regulation, which gave insiders a maximum of 40 days to disclose their trades. The 2-day restriction is motivated by the post-SOX regulation, which gives insiders a maximum of 2 business days to disclose their trades. As expected, we see that insiders are more likely to trade in the same direction if transactions are closer to each other, although these differences are economically insignificant.

In Panel B of Table 4 we address the same question with a standard Probit model, where the dependent variable equals one if the transaction is a purchase, and regress it on the same dummy variable for the previous transaction (LagPurchase). Many papers document the influence of investor sentiment on investment decisions of retail investors and asset prices (see for example Lee, Shleifer, and Thaler, 1991). If insiders behave like retail investors we expect that they buy stocks more frequently if investor sentiment is high and sell stocks more frequently if investor sentiment is low. In contrast, if insiders behave rationally we expect exactly the opposite pattern because insiders may recognize that stocks are mispriced. In regression (2) in Table 4B we control for investor sentiment, by including CCI, the consumer confidence index (following Lemmon and Portniaguina, 2006), and in regression (3) by including Sentiment, the investor sentiment measure of Baker and Wurgler (2006), as independent variables. The insider trading literature has shown that insiders often purchase (sell) shares after 
periods of negative (positive) abnormal stock performance. ${ }^{13}$ Seyhun (2000) calls these contrarian trades passive transactions. We control for this insider behavior by including two additional independent variables in model (4) and (5): past stock performance measured by RunupCAR, the abnormal return over the 20 trading days before the transaction, and StockTercile, which is the tercile of the stock return in the calendar month before the transaction of all sample companies with sufficient data for this period. Both variables measure the relative development of firm's stock price in the month before an insider transaction. Model (6) includes all four control variables.

Across all these regressions, the coefficient of LagPurchase is close to 0.94, which means that the conditional probability that the next transaction is again a purchase is $94 \%$ if we evaluate the impact at the mean of all independent variables. This is economically significantly different from its unconditional probability and statistically significant at all conventional significance levels. The coefficients on $C C I$ and Sentiment are statistically highly significant (both t-statistics in Table 4 are in excess of 29). When including both measures in model (6) the coefficient of Sentiment and its significance is somewhat reduced. These results show that investor sentiment influences insiders similar to retail investors. However, the impact of investor sentiment is economically small: a one standard deviation increase in $C C I$ (Sentiment) increases the likelihood that the next transaction is a purchase by $1 \%(1.1 \%)$. The impact of StockTercile is negative, which shows that insiders are contrarians: if the stock has performed relatively well over the previous calendar month, then they are significantly less likely to purchase additional shares, where an upward move from the bottom to the middle, or from the middle to the top tercile reduces the probability by $2.5 \% .{ }^{14}$ Interestingly, RunupCAR, the return relative to the index before the first transaction has no significant impact. All observations also hold for model (6), which includes all control variables. We therefore conclude from this analysis that stealth trading is pervasive. Insiders are much more likely to purchase (sell) shares if the previous transaction was also a purchase (sale). Our subsequent dis-

13 Rozeff and Zaman (1998), Lakonishok and Lee (2002), Jenter (2005), and Fidrmuc, Korczak, and Korczak (2009) find that insiders on aggregate are contrarian investors.

14 Fidrmuc, Goergen, and Renneboog (2006) find for the U.K. that abnormal returns before insider purchases (sales) are significantly negative (positive) and conclude that insiders can time their trades. 
cussion formulates and tests hypotheses about how stealth trades differ from non-stealth trades and when and why stealth trading occurs.

\subsection{Patterns of stealth trading}

We aggregate sequences of stealth trades into aggregate trades and refer to these as aggregate stealth trades. If we analyze individual trades of a stealth trading sequence, we refer to them as single stealth trades. The aggregation of stealth trades is important because we are interested in the characteristics of the firms, the liquidity of the market for their stock, and the identity of the insiders rather than in the characteristics of individual trades. Aggregating stealth trades is particularly relevant when we wish to compare the volume or stake of stealth trades to those of single trades, because then we are interested in the size of the entire sequence and not only in the size of its components.

Insert Table 5 here

Volume is the volume of a transaction in thousand U.S. \$ and Stake is the percentage of shares outstanding traded in the transaction. The univariate results in Table 5 show that single stealth trades are only about half as large as non-stealth trades (median Volume: \$28,900 vs. \$56,900, median Stake $0.004 \%$ vs. 0.011\%). However, aggregate stealth trades are about four times larger than non-stealth trades (median Volume: $\$ 261,400$ vs. \$56,900, median Stake 0.049\% vs. $0.011 \%)$.

We also use the definition of trade size introduced by Barclay and Warner (1993). They define transactions as small if the number of shares is less than 500, as medium-size if the number of shares is at least 500 but less than 10,000, and as large if at least 10,000 shares are traded. Barclay and Warner (1993) find that the price impact is largest for medium-size trades and conclude that informed traders use stealth trading to camouflage their information by spreading their trades over time. We categorize all trades into three groups: SmallTrade (less than 500 shares), MediumTrade (500 to 9,999 shares), and LargeTrade (10,000 or more shares). The results in Table 5 show that most non-stealth trades (54.7\%) and single stealth trades $(54.3 \%)$ fall indeed into the category MediumTrade, which is in line with Barclay and Warner's results (in their sample $45.7 \%$ of trades are medium-size) and corroborates their presumption that informed traders mostly execute medium-size transactions. However, in our sample small transactions make up only $16.4 \%$ of non-stealth trades and $28.4 \%$ of stealth 
trades, compared to $52.6 \%$ in Barclay and Warner. The main difference between the two samples is that insiders execute many more large trades: $28.9 \%$ of non-stealth trades and $17.3 \%$ of stealth trades, compared to only $1.7 \%$ in the Barclay and Warner sample. Hence, insiders trade on average larger stakes than other investors in the stock market, which is unsurprising given that insiders also includes large shareholders with more than $10 \%$ ownership, who are wealthier and trade large stakes in the company.

\section{Who undertakes stealth trading and when?}

In this section, we develop and test two groups of hypotheses, information-based hypotheses and liquidity-based hypotheses. We develop and test six different hypotheses that potentially explain who undertakes stealth trading and when it is undertaken.

We perform Probit analysis, where the dependent variable is Stealth, which is equal to one if the trade is an aggregated stealth trade, and zero otherwise. The use of this dependent variable is appropriate since insiders probably control whether their orders are split, but they may not control the precise extent to which they are split, which may be left to their intermediaries. Since all hypotheses refer to the same dependent variable, we combine these variables in one regression in order to avoid omitted variable bias. We collect the results in Table 6, but discuss each hypothesis and the respective variables in turn.

Insert Table 6 here

We group variables in Table 6 by the respective hypothesis and order them in the same order as we discuss them in the text. The table reports marginal effects calculated at the mean of all independent variables. In addition to variables associated with our hypotheses, we use two control variables and dummy variables that control for potential industry effects and for calendar years to capture potential time trends. We control for size using LogMarketCap, the logarithm of the market capitalization of the company. We also enter $S O X$, a dummy variable that equals one for the period after August 28, 2002. We report the economic significance in the last column of Table 6. For all continuous variables economic significance is defined as the product of the regression coefficient in regression (3) and the standard deviation of the variable from Table 3. The entries in the last column can therefore be interpreted as the change in the probability of stealth trading from a one-standard deviation increase in the cor- 
responding independent variable. For dummy variables economic significance is simply the coefficient on the variable itself.

Trade size. The most obvious source of price impact is the size of the order an insider wishes to place. It is not possible to assign trade size unambiguously to either information-based or to liquidity-based explanations. Insiders may wish to trade larger stakes because they have stronger informative signals or because of liquidity shocks. In both cases they would tend to break up these orders.

Hypothesis 1 (Trade size): Stealth trading is more likely for larger (in aggregate) trades.

We aggregate the stakes traded into deciles and define StakeDecile, which assigns the decile (highest $=10$, lowest $=1$ ) to each trade. Recall that we refer to aggregate stealth trades, so we compare non-stealth trades to entire stealth trading sequences. StakeDecile is the single most significant variable in all our regressions. ${ }^{15}$ If we move up one size decile, then the probability that this trade is broken up into a sequence of stealth trades increases by $8.8 \%$, so the effect is not only statistically, but also economically large.

\subsection{Information-based hypotheses}

Information hierarchy. Several papers in the insider trading literature investigate the "information hierarchy hypothesis" (Seyhun, 1986), which holds that trades by those insiders who have more information have a higher price impact. ${ }^{16}$ We should therefore expect that insiders who are more informed and who have more information to hide will engage more in stealth trading because they face more adverse selection problems.

Hypothesis 2 (Information hierarchy): Stealth trading is more likely for insiders who are more informed.

15 Using VolumeDecile instead of StakeDecile yields, qualitatively and quantitatively similar results (not tabulated).

16 In the literature on insider trading the information hierarchy hypothesis holds that trades by insiders who are closer to the firm have a larger information content. The evidence on this hypothesis is mixed. Seyhun (1986) shows that the directors and officers trade on more valuable information than other insiders. Lin and Howe (1990) show that trades by the CEO and the officers and directors of the firm have a higher information content than those of unaffiliated shareholders. Fidrmuc, Goergen, and Renneboog (2006) find no evidence for the information hierarchy hypothesis. 
Based on our data we can distinguish between the CEO, officers other than the CEO, directors who are not officers, the chairman of the board, and other insiders who hold none of these roles. These are mostly large shareholders, who have to file their transactions if their ownership exceeds $10 \%$ of the outstanding shares.

The regression analysis in Table 6 includes dummy variables for all categories of insiders except outside directors, so the coefficients for the four remaining insider groups have to be interpreted relative to the outside directors of the company. If we apply the information hierarchy hypothesis to stealth trading, then we should expect the coefficients on $C E O$, Chairman, and Officers all to be positive, because these groups should possess more inside information than the other groups. It is also reasonable to expect that the coefficient on $C E O$ is larger than the coefficient on Officers. By contrast, we expect the coefficient on OtherInsider to be negative as other insiders are only included by virtue of their large shareholdings, but they can obtain inside information only from their privileged access to information from the $C E O$ and from the directors of the company. We find the expected coefficient for $C E O$, but it is sometimes insignificant, dependent on how we control for asymmetric information with different accounting-based measures. The coefficient on Officers is negative and always highly significant, whereas the coefficient on OtherInsider is always positive and also highly significant. Both findings contradict the information hierarchy hypothesis. The coefficient on Chairman is always insignificant. The results for Officers and OtherInsider therefore contradict the information hierarchy hypothesis, and those for CEO and Chairman lend no support, so overall our results are inconsistent with the implications of information hierarchy hypothesis. Insiders with more access to information use stealth trading less, and those with less access to information use it more.

We suspect that the reasons for our findings are that the less informed insiders hold larger stakes and therefore also conduct larger transactions. We find this to be the case. Other insiders trade on average $\$ 416,100$ or $0.083 \%$ of the company's shares, which compares to $\$ 294,000(0.026 \%)$ for the CEO, and $\$ 262,100(0.021 \%)$ for other officers, and $\$ 279,300$ $(0.033 \%)$ for outside directors. Only chairmen of the board trade similar dollar volumes of $\$ 420,500$, although these account still for only $0.029 \%$ of their companies' shares. This find- 
ing is more indicative of concerns about liquidity and price impact, an argument we develop in more detail below.

Direction of trade. The insider trading literature has shown that purchases have a larger information content compared to sales, probably because sales are more likely to be motivated by liquidity considerations, whereas purchases are more likely to be motivated by information advantages. ${ }^{17}$ If stealth trading is a strategy to hide trades with a larger information content, then stealth trading should be related to the direction of trades.

Hypothesis 3 (Direction of trade): Stealth trading is more frequent for purchases than for sales.

We define Purchase as a dummy variable, which equals one for purchases and zero for sales. Table 6 shows that the coefficient of Purchase has the predicted sign in all specifications. The impact is economically small though: Stealth trading is about $0.82 \%$ to $1.69 \%$ more likely for purchases than for sales.

Asymmetric information and opacity. Stealth trading should be more attractive if the general scope for informed trading is larger. This will be the case if there is more asymmetric information, for example in companies that are more opaque, and in companies with more firmspecific risk. Earnings announcements disclose significant new information, so that there should be more asymmetric information before earnings announcements. We therefore expect more stealth trading before earnings announcements and less stealth trading immediately after earnings announcements. ${ }^{18}$

Hypothesis 4 (Asymmetric information and opacity): Stealth trading is: (1) more likely if there is more asymmetric information and if the company is more opaque; (2) more likely in stocks with more firm-specific risk; (3) more likely before and less likely after earnings announcements.

17 The first to make this observation was Rogoff (1964). See Lakonishok and Lee (2001), Jeng, Metrick, and Zeckhauser (2003) or Fidrmuc, Goergen, and Renneboog (2006) for more recent analyses. The only study to find different results is Cheng, Nagar, and Rajan (2007), who find significant disclosure day returns for sales, but not for purchases. However, they analyze Form-5 transactions, which are different from ours.

18 Aboody and Lev (2000) show that insider gains are larger for R\&D-intensive firms and interpret R\&D as a proxy for asymmetric information. Fidrmuc, Goergen, and Renneboog (2006) and Betzer and Theissen (2009) investigate the impact of news announcements on insider trading. 
We investigate part (1) of Hypothesis 4 by looking at a range of measures of opacity. We use two measures of the quality of earnings disclosure. The first measure is AccrualsQuality, the measure of accruals quality developed by Dechow and Dichev (2002) as amended by McNichols (2002), which measures the forecast error of abnormal accruals. The assumption behind this measure is that working capital accruals are more accurate forecasts of cash flows if the residuals of a regression of changes in working capital on realized cash flows and other controls are small. The measure of accruals quality is therefore the standard deviation of residuals from this regression. The difficulty with AccrualsQuality in our context is that its computation requires accounting numbers that are not available for all firms in our sample, so that sample size is reduced by almost $40 \%$. Our second measure of accounting disclosure quality is AQLoading and overcomes this limitation by using a factor mimicking approach. This measure was developed by Ecker et. al. (2006), who use the Dechow and Dichev (2002) measure of accruals quality to sort firms into deciles. They then construct an accruals quality factor as the difference of the stock returns between the highest four deciles and the lowest four deciles of accruals quality. AQLoading for any firm is then defined as the slope coefficient from a regression of the firm's excess stock return on the accruals quality factor after controlling for the standard Fama-French factors. We explain the construction of AccrualsQuality and AQLoading in more detail in the appendix. In the robustness section, we also report a specification that uses the modified Jones (1991) model to measure disclosure quality.

Both measures of accounting disclosure quality in Table 6 are marginally significant with t-statistics between 1.70 and 1.92, which is small, in particular in view of the large sample size. The effects are also economically small: A one-standard deviation increase in AccrualsQuality increases the probability of stealth trading by $0.3 \%$, and a one-standard deviation increase in AQLoading increases the probability of stealth trading by $0.2 \%$. Hence, opacity as measured by AccrualsQuality and AQLoading has at most a small impact on the probability of stealth trading.

We use two microstructure measures of information asymmetry. The first is InformationComponent, Stoll's (2000) measure of the information component of the quoted spread. This measure is statistically insignificant in regressions (1), (2), (4), and (5) in Table 6. The 
second measure is PIN, the probability of informed trading introduced by Easley et. al.(1996). We describe the calculation of both measures in more detail in the appendix. PIN is marginally significant in the smaller sample where we control for disclosure quality by AccrualsQuality, and completely insignificant in the larger sample where we control for disclosure quality by AQLoading.

Furthermore, $R \& D$ is defined as research and development expenditures scaled by total assets. $R \& D$ is set to zero for those firms where Compustat does not report any research and development expenditures, so that we measure this variable with some error. The results are still statistically highly significant and in line with the predictions from Hypothesis 4 . However, economic significance is again small: a one standard deviation increase of $R \& D$ increases the probability of stealth trading by about $0.6 \%$.

We analyze part (2) of Hypothesis 4 by using Volatility, defined as the annualized standard deviation of daily stock returns over the calendar month preceding the transaction. We use this as a measure of firm-specific risk. ${ }^{19}$ The effect is significant with the predicted positive sign, so more volatile firms have more stealth trading: A one-standard deviation increase in volatility leads to an $0.6 \%$ increase in the probability of stealth trading.

We analyze Part (3) of Hypothesis 4 by looking at earnings announcements reported by Compustat. We define two dummy variables BeforeEarnAnnounce and AfterEarnAnnounce, which equal one for a period of two weeks (14 days) before, respectively, after an earnings announcement. The coefficient for BeforeEarnAnnounce is always positive. It therefore seems that insiders use stealth trading more frequently in periods when there is more asymmetric information. However, we do not find that insiders use less stealth trading after earnings announcements, when asymmetric information should be less severe, which contradicts Hypothesis 4 and the notion that stealth trading is used more in an environment where information asymmetry is larger. The coefficient of AfterEarnAnnounce is positive and significant across all models.

19 Results do not change materially if we use the standard deviation of daily excess returns from a market model as a proxy for firm specific risk, where we use the CRSP-value weighted index over the preceding calendar year as a measure of market risk. 


\subsection{Liquidity-based hypotheses}

Liquidity. We expect that stealth trading is more attractive if the price impact of trades is large, which is the case in illiquid markets and for larger trades. The attractiveness for insiders to break up larger trades rather than smaller trades is further increased if there are fixed costs from trading.

Hypothesis 5 (Liquidity): Stealth trading is more likely in less liquid stocks.

Liquidity is a somewhat elusive concept and the literature has developed different measures. ${ }^{20}$ We use only two different measures in Table 6 to conserve space and report results for another five measures in the robustness section. The first proxy is EffectiveSpread, which is defined as $\mathrm{ES}_{\mathrm{t}}=2\left|\mathrm{P}_{\mathrm{t}}-\mathrm{Q}_{\mathrm{t}}\right| / \mathrm{Q}_{\mathrm{t}}$, where $\mathrm{Q}_{\mathrm{t}}$ is the midpoint of the quotes and $\mathrm{P}_{\mathrm{t}}$ is the price at which the transaction is executed (see Chordia, Roll, and Subrahmanyam, 2001). The second proxy is QuotedSpread, which is the quoted relative spread, i.e., the difference between the bid price and the ask price, scaled by the midpoint. We average both spread measures for all trades during the day and assign the spread measure of the first day of a stealth trading sequence to the aggregated stealth trade.

A limitation of testing Hypothesis 5 with our methodology is that both, EffectiveSpread and QuotedSpread may also be higher because traders anticipate the arrival of informed traders. We attempt to control for the information component of the spread by entering InformationComponent as well as PIN, but these controls may be imperfect. We therefore want to break up the quoted spread into a component related to information and a pure liquidity component. We do this by interacting InformationComponent with QuotedSpread. QuotedSpread is a relative spread since it is scaled by the midpoint, and InformationComponent is defined to lie between zero and one, so that the interactive term can be interpreted as the informationrelated portion of the quoted spread. We also enter the complement, i.e. (1InformationComponent)*QuotedSpread, which we then interpret as the non-information related component of the spread. We also used the decomposition of the effective spread proposed by Lin, Sanger, and Booth (1995) and find similar results (not tabulated).

20 See Goyenko, Holden, and Trzcinka (2009) for a recent analysis of liquidity measures. 
Stealth trading is more prevalent in firms with illiquid stocks. The effects are statistically highly significant independently of the spread measure chosen. Our results are therefore in line with Hypothesis 5. The economic effects are several times larger than those for many of the information-related variables we discussed above, but still not nearly of the same magnitude as trade size itself.

Trading environment. We expect that the inclination to break up trades depends also on the competition for liquidity in the market. It should be easier to sell shares in rising markets when there is more demand, and to buy shares in falling markets, when there is a larger supply. It will be on average more difficult to be on the short side of the market, i.e., buy when other investors want to buy and vice versa. Hence, we expect that stealth trading is more likely if insiders are on the short side of the market. ${ }^{21}$ We also hypothesize that that insiders wish to split their trades if several insiders trade at the same time. We can see several reasons why insiders may trade simultaneously. First, many companies impose blackout periods that restrict the time windows where insiders are allowed to trade, e.g. after earnings announcements, so that insiders trade simultaneously in the same trading window. ${ }^{22}$ Second, many insiders exercise stock options and sell their shares at the same time when they receive new stock options. ${ }^{23}$ This event typically occurs on the same date for all insiders of the same firm. In principle, insiders may also trade at the same time because they simultaneously observe the same information, but this should not lead to more stealth trading. In fact, the theoretical analysis of Holden and Subrahmanyam (1992) shows that in a market where multiple insiders try to profit from the same long-lived information, insiders concentrate their trades into a shorter period of time and therefore engage in less stealth trading.

Hypothesis 6 (Trading environment): (1) There is more stealth buying in rising markets and more stealth selling in falling markets. (2) There is more stealth trading if more insiders trade in the same direction at the same time.

21 See Chiyachantana et. al. (2004) and Chakravarty, Kalev, and Pham (2005).

22 Bettis, Coles, and Lemmon (2000) show that about 92\% of their sample firms impose trading restrictions for insiders and that the most common trading window is 3 to 12 days after earnings announcements.

23 See Ofek and Yermack (2000) for stock sales after option exercises and Klein and Maug (2009) for stock sales and exercises of existing options when executives receive new options. 
We cannot measure the direction in which other traders want to trade directly and infer it from recent price movements instead. We conduct this analysis at the firm level and classify insider transactions according to the recent share price performance of the insider's company assuming that it is more difficult for insiders to buy (sell) shares if the stock of their company has over (under) performed compared to all other stocks in the market. We classify a stock as overperforming if its return was in the top tercile of all stock returns in the sample in the month before the transaction. Analogously, a stock is underperforming if its return was in the bottom tercile in the previous month. (This classification corresponds to one used in the definition of StockTercile, which we used above.) We then define a dummy variable ShortSide, which equals one if the transaction is on the short side of the market, i.e., if the transaction is a purchase and the stock was over performing, and also if the transaction is a sale and the stock was underperforming. Under Hypothesis 6, we should see that the coefficient on ShortSide is positive, so that there is more stealth buying if the stock outperformed and more stealth selling if the stock underperformed. The results in Table 6 show that the coefficient of ShortSide always has the predicted sign and it is highly significant in all regressions. We therefore conclude that insiders use stealth trading more often when they are on the short side of the market for their own stock.

Hypothesis 6(2) holds that insiders tend to use more stealth trading if other insiders also trade in the same direction. This claim is corroborated by the positive and highly significant coefficient for the dummy variable MultipleInsiders, which is one if more than one insider trades in the same direction on the same day. The impact of this variable is statistically and economically large. The likelihood of stealth trading increases by more than $5 \%$ if at least one other insider is trading in the same direction.

We believe that these explanations can also help to understand the puzzling finding that the coefficient on AfterEarnAnnounce has a positive sign, the opposite of what we predict in Hypothesis 4(3) under the assumption that the impact of this variable is driven by informational considerations. If companies restrict trading windows to a period after their earnings announcements, or if all insiders receive new options and therefore sell stock from exercising their old options, then insiders of such companies know that many other insiders will trade simultaneously. From Table 3 we can see that the mean of AfterEarnAnnounce is 0.200, so 
$20.0 \%$ of the sample transactions are executed in the two weeks after an earnings announcement. With a uniform distribution of trades over the year and four earnings announcements per year, we should expect only $15.4 \%$ of all transactions to be executed in the two weeks after an earnings announcement. ${ }^{24}$ Insider trades are therefore biased to the weeks after earnings announcements. In such a situation stealth trading offers insiders the possibility to reduce the price impact of their transactions by matching them with those of more liquidity traders.

\subsection{Comparison of explanatory power}

We find strong evidence supporting the interpretation that insiders split their trades to take better advantage of market liquidity and reduce price impact, but also some evidence in favor of information-based explanations. We now compare the explanatory power of both groups of hypotheses by employing two different methodologies and report the results in Table 7 .

Insert Table 7 here

Both methods rely on regression (3) in Table 6 as our baseline specification. We choose this regression because it splits the spread into an information component and a pure transaction cost component, so that all variables can be assigned either to the information-based explanations or to liquidity-based explanations. We then estimate restricted models where we remove either the information-related variables or the liquidity-related variables. For the informationbased explanations we separately remove those variables that have the predicted sign in the baseline regression according to our hypotheses, and then the variables that have the opposite sign compared to our predictions.

We report two tests. First, we report the likelihood ratio test statistic, which is twice the drop in the log-likelihood from removing the variables in the restricted regression. Second, we estimate linear probability models, which allow us to calculate the R-squareds of each regression. We do not report the coefficient estimates for the linear probability models, which are similar to those from the Probit models. We then report the partial R-squared, which we define as the decrease in the R-squared from excluding variables in the restricted regression.

The results in Panel A of Table 7 show that most of the explanatory power comes from liquidity-related variables. The comparison shows that the liquidity-based variables have

${ }^{24}$ About $99.9 \%$ of our sample transactions come from firms that file quarterly reports; therefore, 8 out of 52 
jointly more explanatory power than the information-based variables. First, all liquidityrelated variables have the predicted sign, whereas several information-related variables do not. Second, the explanatory power of the liquidity-related variables is larger than those of information-related variables that have the predicted sign: The likelihood ratio test statistic for liquidity-related variables is more than three times larger (782 compared to 242) and the partial R-squared is about twice as large $(0.31 \%$ compared to $0.16 \%)$ compared to the corresponding statistic for information-related variables.

\section{Extensions and robustness checks}

\subsection{Stealth trading before and after the Sarbanes-Oxley Act}

We are interested in whether stealth trading was affected by the passage of the SarbanesOxley Act. ${ }^{25}$ We first split the sample into pre-SOX transactions before August 28, 2002 and into post-SOX transactions after that date. Again, we choose regression (3) from Table 6 as our baseline specification.

Insert Table 8 here

We find differences for some of the coefficients. The most interesting impact is on the behavior of insiders. The coefficient on Officer is negative only after SOX. Interestingly, the coefficient on Chairman, which is insignificant if we run the regression on the entire sample period, is now significant, with a positive sign before SOX and a negative sign after SOX. Hence, the coefficients on Officer and Chairman are consistent with the information hierarchy hypothesis before SOX, but not after SOX. Stealth trading by OtherInsiders declines by about $40 \%$ after SOX.

Some of the variables related to asymmetric information also change. The coefficient on Volatility is significant only before SOX and the coefficients on BeforeEarnAnnounce and AfterEarnAnnounce both decline dramatically and BeforeEarnAnnounce becomes insignificant. This is also consistent with the notion that insiders became more cautious to use stealth trading around information sensitive events like earnings announcements. In Panel B of Table

weeks per calendar year (15.4\%) fall into the category AfterEarnAnnounce.

25 A recent literature investigates the impact of the Sarbanes-Oxley Act on insider trading as well as a range of other governance-related issues. See Cheng, Nagar, and Rajan (2007) and Brochet (2008) on insider trading and Brockman, Martin, and Puckett (2008) on stock option exercises. 
7 we repeat all tests from Panel A of the same table separately for the period before and after SOX. Interestingly, we find that the explanatory power of all hypotheses is reduced, but that for liquidity-based explanations declines more than that for information-based explanations.

Our suspicion from this analysis is that the sample split into a pre-SOX and a post-SOX period may capture other developments than the incidence of SOX. In particular, liquidity increases by all measures we employ: EffectiveSpread declines by almost 50\% from $1.4 \%$ to $0.8 \%$ and Turnover is higher by $25 \%$ in the post-SOX period. These changes may be related to an increase in computerized trading and a general reduction in transaction costs and may therefore be unrelated to SOX. To test for this, we split the sample into transactions where EffectiveSpread is above the median and those where EffectiveSpread is below the median. The correlation between the sample split according to EffectiveSpread and according to the passage of SOX is sufficiently low to permit a separate analysis. ${ }^{26}$ Regressions (3) and (4) of Table 8 show that our suspicion is justified. In fact, the changes in the coefficients for all categories of insiders suggest that all insiders use stealth trading less compared to directors after SOX and when markets are more liquid. Also, BeforeEarnAnnounce, and ShortSide behave similarly for a pre/post-SOX split and split into high/low EffectiveSpread subsamples. We therefore conclude that the association of changes in these variables with the SarbanesOxley act is spurious. There is a large increase in the coefficient on $R \& D$ in the high liquidity subsample, which is not matched by a corresponding increase in the post-SOX period. Also, the large decline in the coefficient on Volatility in the post-SOX period does not seem to be related to an increase in liquidity.

We are also interested in other dimensions in which insiders' behavior may have changed because of SOX. Most likely, insiders benefit from concealing their trades from other traders is lost or at least diminished once the first trade is disclosed, and after SOX insiders have only two business days instead of up to 40 days until they have to disclose their trades (see Section 2.1 above). We therefore hypothesize that stealth trading declines after SOX became effective and that insiders attempt to squeeze stealth trades into a shorter period. Univariate comparisons suggest that this is the case (results not tabulated). The time span be- 
tween the first and the last trade of a stealth trading sequence declines from 8.14 days to 1.33 days, as expected. The time between two consecutive stealth trades declines from 1.89 days to 0.17 days. At the same time, stealth trades become smaller by all measures (volume and stake per transaction and also for aggregate sequences of trades). However, we cannot be sure that these changes are causally related to SOX because these developments may reflect a general time trend.

\section{Insert Figure 1 here}

Panel A of Figure 1 shows a positive trend in the proportion of stealth trades of all insider transactions that begins in 1998 and continues until the end of our sample period, without indicating a structural break at any particular date. The decline between 2002 and 2004 does not seem to be related to SOX and the temporary drop in the time series occurs several months later, in January 2003. The number of transactions in a stealth trading sequence in Panel B also increases and triples from about 4 to about 12 during our sample period, without showing any clear relation to SOX. We therefore expect that the change in transaction technologies, especially computerized trading, and the possibility to execute a larger number of transactions automatically drive stealth trading and that SOX had little influence on these developments.

We address the impact of SOX more rigorously by running time-series regressions. We aggregate variables by calculating averages across all transactions in a particular calendar month and then estimate a simple AR(1) process for each. We add Trend, a deterministic trend, which is defined as the number of months from the beginning of our sample period, and the $S O X$ dummy, which equals one after SOX and zero before.

Insert Table 9 here

We define StealthVolume as the size in dollars of the aggregate volume of a stealth trading sequence, and StealthProportion as the ratio of the dollar volume of all stealth trades relative to the dollar volume of all insider trades in a given month. The impact of SOX on StealthVolume is insignificant if we control for a time trend, but not if Trend is not included (Panel B). StealthProportion fluctuates in the $75 \%$ to $85 \%$ range before SOX and regression (2) im-

26 For 265,436 or $62 \%$ of the trades in the sample where stealth trades are aggregated, the split according to EffectiveSpread is the same as the one according to SOX whereas for 162,284 (38\%) of the sample these splits differ. 
plies that SOX causes a decline of $13.8 \%$ in the proportion of stealth trades relative to all insider trades. Regression (3) shows that TimeSpan, the number of days between two stealth trades declines by 0.88 days because of SOX, a result we expected because disclosure is now more timely. Delay, the difference in days between the transaction date and the reporting date declines by 20.22 days after SOX, so the new disclosure regulation has a strong effect.

Altogether, these results show that insiders moderately reduced the usage of stealth trading after SOX. The strongest impact of SOX is that insiders split their transactions into a larger number of smaller trades, execute these trades faster, so that trades became more concentrated in a much shorter time span. They then disclose these trades sooner to comply with the new regulation. Most other changes during our sample period seem to be the results on a steady trend towards higher market liquidity and unrelated to the Sarbanes-Oxley act.

\subsection{Stealth Trading on NYSE and on NASDAQ}

We would like to compare our main results for stocks listed on the New York Stock Exchange (NYSE) to those listed on NASDAQ. We therefore run regression (3) from Table 6 separately for NYSE stocks and for NASDAQ stocks and report the results in Table 8. Regression (3) shows the results for the NYSE subsample and regression (4) shows the results for the NASDAQ subsample. Most coefficients have the same signs and significance levels as in Table 6, but there are some noteworthy differences. For NASDAQ firms the interactive term with InformationComponent is larger than for NYSE firms, whereas the non-information related part is larger for NYSE firms. Similarly, the effects of CEO, Purchase, Volatility, R\&D, and SOX are all stronger for NASDAQ firms than they are for NYSE firms. In fact, the coefficients for $S O X$ become insignificant for NYSE firms and the coefficient for Volatility even changes signs.

Our findings support the notion that information-based explanations have more explanatory power for NASDAQ firms than for NYSE firms. This is plausible, as we would expect NASDAQ firms to be smaller, more volatile, and more opaque firms. We test for this by repeating the analysis with likelihood ratio tests and partial R-squareds in Panel C of Table 7. Our conjecture is only partially correct. While the statistics for information-related variables that have the predicted sign is much larger in the NASDAQ sample than in the NYSE sample, those variables that have the opposite of the predicted sign for the NASDAQ sample also be- 
come more significant. In particular, officers use stealth trading much less in the NASDAQ sample. Liquidity-related variables have the same explanatory power for companies on both exchanges.

\subsection{Robustness checks}

We perform a range of robustness checks on our empirical design. Our first concern is that the definition of the dependent variable defines stealth trading differently for the period before and after SOX because our definition depends on the actual disclosure date. We argue above that this is justified because trades are no longer stealth once the first trade in a sequence has to be disclosed. We now take a different approach and define Stealth to equal one for a sequence of trades within seven days of the first trade, independently of whether any trades were disclosed in the meantime or not.

\section{Insert Table 10 here}

Table 10 shows the results for the alternative definition of Stealth. The changes compared to Table 6 are mostly small. The coefficient on $C E O$ declines in magnitude and also in significance, as does the coefficient on Purchase. The coefficient on AQLoading doubles in size and becomes significant, but the economic significance is still modest. The coefficient on BeforeEarnAnnounce changes signs and becomes insignificant. None of these results affects our conclusions materially and we conclude that our findings are robust to the definition of the dependent variable.

We use AccrualsQuality and AQLoading as measures of accounting disclosure quality in Table 6. Another commonly used measure is AbnormalAccruals, the prediction errors from forecasts from the modified Jones (1991) model. For better comparison with the literature, we report the results for AbnormalAccruals in regression (2) of Table 10. AbnormalAccruals itself is completely insignificant and does not seem to pick up any relevant aspect of opacity for our purposes. For the other coefficients, there are hardly any noteworthy changes. The only variables that are statistically significant and change by more than $40 \%$ in magnitude are $A f$ terEarnAnnounce, which increases from 0.0119 to 0.0166 , and Volatility, which increases from 0.0110 to 0.0170 . Most likely, these variables now capture aspects of asymmetric information and opacity that were picked up by AQLoading in the baseline regression in Table 6 . 
Our choice of liquidity measures in Table 6 was also highly selective and we employ a range of other liquidity measures and report the results in regressions (3) - (7) of Table 10. We use the Amihud measure based on Amihud (2002), which is defined as the ratio of the daily absolute return to the dollar trading volume on that day (regression 3). Following the argument of Lesmond, Ogden, and Trzcinka (1999), LOT measures the roundtrip transaction costs for buying and selling, which are estimated using maximum likelihood (regression 4, see the appendix). We estimate the measure of price impact proposed by Stoll (2000) as a coefficient from the regression of the daily price change on the daily trade imbalance between share volumes of purchases and sales on day $t$. Some of the literature relates trading volume to market liquidity (e.g., Brennan and Subrahmanyam, 1995), although the strength and significance of this relationship is not clear (for a critical point of view see Lesmond, 2005). We include Turnover, defined as the total number of shares traded on the day of the transaction divided by the total number of shares outstanding (regression 6). The theoretical justification for Lambda follows from Kyle (1985) and our calculations follow the regression approach of Lin, Sanger and Booth (1995). We use their measure Lambda as a measure of the information component of the effective spread as well as their measure Gamma as the order processing cost component of the spread (see the appendix and regression 7).

All liquidity measures except PriceImpact are highly significant with t-statistics ranging from 2.17 for Amihud to 12.04 for Gamma. The less liquid a stock is, i.e., the higher the spread and the lower turnover, the higher is the incidence of stealth trading, showing that stealth trading is concentrated in infrequently traded, illiquid stocks. We also check for economic significance by multiplying the coefficients on the liquidity measures in Table 10 with their standard deviations to evaluate the impact of a one-standard deviation change in the respective liquidity measure. Interestingly, Turnover has the largest impact on the likelihood of stealth trading: A one-standard deviation increase in Turnover reduces the probability of stealth trading by $3.7 \%$. Our conjecture is that insiders monitor trading volume as a proxy for liquidity, and then place stealth trades at times when volume is low, but place larger trades and non-stealth trades when volume is high. The coefficients on the other variables are not greatly affected by the inclusion of particular liquidity measures and we conclude that our results are robust to our choice of liquidity measure. 


\subsection{Price impact on disclosure dates}

If the motivation behind stealth trades is to conceal information, then stealth trades should systematically contain more information than non-stealth trades. We should therefore expect that the disclosure of stealth trades contains a stronger signal than the disclosure of nonstealth trades. We measure the impact on stock prices by using standard event study methods. Abnormal returns are calculated over a 1-day event window using market model benchmark returns calculated with the CRSP value-weighted index. The event day is the disclosure of the first trade in a stealth trading sequence or the disclosure date of non-stealth trades. We calculate abnormal returns on the disclosure date separately for purchases (PurchaseAR) and for sales (SalesAR).

\section{Insert Table 11 here}

From the point of view of information-based explanations the impact of disclosing stealth sales should be more negative than non-stealth sales, and the impact of stealth purchases should be more positive than that for non-stealth purchases. We therefore run separate regressions for purchases and for sales and expect a negative sign for sales and a positive sign for purchases. The results from regressions in Table 11 suggest that stealth trades do not have more information content than non-stealth trades. The coefficients for Stealth are economically insignificant in all regressions. The coefficient for Stealth has different signs for univariate regressions than for multivariate regressions; it only has the predicted sign in the univariate regressions, but is then statistically insignificant for sales. Therefore, we find no support

for the hypothesis that stealth trades contain more information than non-stealth trades. There is no discernible difference in the information impact of insiders' stealth trades and their nonstealth trades.

\section{Conclusion}

Our analysis provides direct evidence that insiders in the U.S. engage in stealth trading and split large orders into sequences of smaller transactions. Almost $87 \%$ of all insider transactions are part of a sequence of stealth trades during our sample period from 1996 to 2006 . We distinguish between two groups of explanations. Information-based explanations hold that insiders have private information about the fundamental value of the stock and therefore split 
their trades in order to maximize the profitability of their trades. By contrast, liquidity-based explanations argue that insiders act like discretionary liquidity traders who spread small transactions to reduce the temporary price impact that occurs for microstructure reasons and is unrelated to asymmetric information.

We develop several hypotheses that all emphasize the information content of trades and argue that insiders should use stealth trading with more access to private information, more for purchases than for sales, and more in firms that are more opaque and where informational asymmetries are larger. Some of our findings support the assumption that insiders use stealth trading more if they want to conceal information. The results on firms' disclosure quality weakly support information-based explanations but depend on the particular measure of disclosure quality we choose. The insider trading literature argues that purchases are more likely to be driven by fundamental inside information compared to sales, which are more likely driven by liquidity considerations. Consistent with information-based explanations we find more stealth trading for purchases than for sales, although this finding is concentrated in the pre-SOX period where market liquidity is lower. Other findings are inconsistent with information-based explanations. The insider trading literature argues that the CEO and the officers of the company possess more information compared to other insiders. However, we find that those insiders use stealth trading most who are not officers or directors of the company and who should have the least access to information. Finally, we also expect that stealth trades reveal more information than non-stealth trades, but we find no support for this hypothesis from looking at stock price reactions to the disclosure of stealth trades compared to the disclosure of non-stealth trades.

With respect to liquidity-based explanations, we hypothesize that insiders break up trades when their orders are large when the stock is less liquid for reasons other than information asymmetry. We find evidence for both hypotheses, independently of which liquidity measure we use. Insiders use stealth trading more frequently when they are on the short side of the market, i.e. when they purchase in rising markets and when they sell in falling markets. They also use stealth trading more when several insiders trade the same stock at the same time, particularly in the period after earnings announcements. Finally, the insiders with the highest inclination to engage in stealth trading fall into the category of "other insiders," 
mostly large shareholders who are not officers or directors of the company. While they have less direct access to information, they do trade larger stakes. Overall, we find that the explanatory power of liquidity-based explanations is higher than that of information-based explanations, but it declines in the second half of the sample where liquidity is higher.

There are some limitations inherent in our research design. We cannot determine whether stealth trading is successful in reducing price impact. For this, we would have to compare the price impact of stealth trades to the hypothetical price impact of the same order had it not been broken up. There is no good methodology we know that would allow us to conduct this counterfactual analysis.

In this paper, we analyze a very specific group of investors. Our focus on insiders allows us to track their trading behavior with greater precision than we could do for other investors, but the specific characteristics of insiders may limit the extent to which we can generalize our conclusions. It seems plausible that insider trades have a higher likelihood of being induced by private information than trades by other shareholders, which would bias our findings in favor of information-based explanations of stealth trading.

Finally, we cannot address the methods insiders use in order to break up their trades. Very large trading sequences like the one by Eric Schmidt we mention in the Introduction suggest that some insiders use computerized algorithms, but the median stealth trading sequence has only three trades. We expect that a significant part may be undertaken by intermediaries on behalf of insiders. More research, and probably more detailed data, is necessary to address these questions. 


\section{Appendix: Computational routines for variables}

For all microstructure variables, we use the TAQ database, provided by the NYSE, to extract the necessary intraday transaction data. For each trade we assign the bid and ask quotes prevailing at least one second before the trade took place. ${ }^{27}$ The final data set contains the following items for each transaction:

1) Date and timestamp (up to seconds)

2) Transaction price $\left(P_{t}\right)$

3) Transaction volume in shares $\left(w_{t}\right)$

4) Prevailing bid quote $\left(B_{t}\right)$

5) Prevailing ask quote $\left(A_{t}\right)$

We calculate the quote midpoint $\left(Q_{t}\right)$ as the average of the prevailing bid and ask quotes $\left(Q_{t}=\frac{A_{t}+B_{t}}{2}\right)$. We use Lee and Ready's (1991) algorithm to classify trades into buys and sells. We classify trades with a transaction price above the quote midpoint $\left(P_{t}>Q_{t}\right)$ as buys and those with a transaction price below the quote midpoint $\left(P_{t}<Q_{t}\right)$ as sells. If a transaction price is equal to its quote midpoint, we compare the current transaction price with the previous transaction price. If the current one is below the previous one $\left(P_{t}<P_{t-1}\right)$, we consider it to be a sell; if it is above the previous one $\left(P_{t}>P_{t-1}\right)$, we consider it to be a buy.

\section{Decomposing the effective spread (Lin, Sanger, and Booth 1995)}

Lambda $(\lambda)$ represents the adverse selection component as a percentage of the effective spread. Following Lin, Sanger, and Booth (1995), we estimate it as a coefficient from the regression of change in quotes on the one-half signed effective spread $\left(z_{t}=p_{t}-q_{t}\right)$ :

$$
q_{t+1}-q_{t}=\lambda \cdot z_{t}+e_{t+1},
$$

27 Henker and Wang (2005) consider this procedure to be more appropriate compared to the classical Lee and Ready (1991) five-second rule. Bessembinder (2003) tries zero- to thirty-second delays in increments of five seconds and does not find any differences in the results. 
where $q_{t}$ is the logarithm of the quote midpoint at time $t$ and $p_{t}$ is the logarithm of the transaction price at time $t$.

Theta $(\theta)$ measures order persistence. It is estimated as a coefficient from the following AR(1) process:

$$
z_{t+1}=\theta z_{t}+\eta_{t+1}
$$

The error terms $e_{t+1}$ and $\eta_{t+1}$ are assumed to be uncorrelated.

Gamma $(\gamma)$ reflects the order processing costs as a percentage of the effective spread. We estimate it as a coefficient from the regression of difference in transaction prices on the onehalf signed effective spread $\left(z_{t}=p_{t}-q_{t}\right)$ :

$$
p_{t+1}-p_{t}=-\gamma \cdot z_{t}+u_{t+1}
$$

\section{Information Component (Stoll 2000)}

The information component of the quoted spread is a daily measure, which we calculate as:

$$
\text { InfoComp }=1-\frac{\text { TradedSpread }}{\text { QuotedSpread }}
$$

where TradedSpread $=\frac{1}{m} \sum_{t=1}^{m}\left(P_{t}^{A}\right)-\frac{1}{n} \sum_{t=1}^{n}\left(P_{t}^{B}\right)$ and QuotedSpread $=\frac{1}{T} \sum_{t=1}^{T}\left(A_{t}-B_{t}\right)$.

$T$ denotes the total number of transactions over the day, $m$ - the number of transactions at the ask (buys) and $n$ - the number of transactions at the bid (sells), so that $T=m+n \cdot{ }^{28} P^{A}{ }_{t}$ is the transaction price at the ask (the transaction price of a buy) and $P^{B}{ }_{t}$ is the transaction price at the bid (the transaction price of a sell). Our definition gives all trades the same weight. As robustness check, we also calculate volume-weighted averages and obtain similar results.

\section{PIN (Easley et al. 1996)}

The probability of informed trading is the ratio of informed traders to the total number of traders of a particular stock:

28 Please note that $T$ is the same for transactions and for quotes, since each transaction is associated with the single prevailing bid and ask quote. We do not include the non-matched quotes in our analysis, because we believe that only those quotes matter at which a transaction takes place. 


$$
P I N=\frac{\alpha \cdot \mu}{\alpha \cdot \mu+2 \cdot \varepsilon}
$$

where $\alpha$ is the probability of arrival of new information, $\mu$ is the arrival rate of informed traders and $\varepsilon$ is the arrival rate of liquidity-based buyers and sellers (here: assumed to be identical). We estimate these parameters by maximizing the likelihood function as derived by Easley et al. (1996):

$$
\begin{aligned}
L(B, S) & =(1-\alpha) * e^{-\varepsilon T} \frac{(\varepsilon T)^{B}}{B !} e^{-\varepsilon T} \frac{(\varepsilon T)^{S}}{S !} \\
& +\alpha \delta * e^{-\varepsilon T} \frac{(\varepsilon T)^{B}}{B !} e^{-(\mu+\varepsilon) T} \frac{[(\mu+\varepsilon) T]^{S}}{S !} \\
& +\alpha(1-\delta) * e^{-(\mu+\varepsilon) T} \frac{[(\mu+\varepsilon) T]^{B}}{B !} e^{-\varepsilon T} \frac{(\varepsilon T)^{S}}{S !}
\end{aligned}
$$

where $B$ denotes the number of buys over the day $I$ and $S$ denotes the number of sells over the day $I$. The parameter $\delta$ is the probability that the information is negative. Since days are considered to be independent, the likelihood function over $I$ days is simply the multiplication of $I$ daily likelihood functions. We obtain convergence for $96 \%$ of all 106,634 firm-quarters. ${ }^{29}$

\section{LOT (Lesmond, Ogden and Trzcinka 1999)}

According to Lesmond, Ogden and Trzcinka (1999), the LOT measure represents the proportional round-trip transaction costs for the marginal investor:

$$
L O T=\alpha_{2 j}-\alpha_{1 j}
$$

where $\alpha_{1 j}\left(\alpha_{2 j}\right)$ is the threshold for trades on the negative (positive) information of the firm $j$ 's stock. We estimate both of these parameters by maximizing the following likelihood function:

29 We use a SAS program, published on the web-site of Noah Stoffman, http://kelley.iu.edu/nstoffma/. 


$$
\begin{aligned}
L\left(\alpha_{1 j}, \alpha_{2 j}, \beta_{j,} \sigma_{j}\right. & \left.\mid R_{j t}, R_{m t}\right)=\prod_{R_{1}} \frac{1}{\sigma_{j}} \phi\left[\frac{R_{j t}+\alpha_{1 j}-\beta_{j} \cdot R_{m t}}{\sigma_{j}}\right] \\
& \times \prod_{R_{0}}\left[\Phi_{2}\left(\frac{\alpha_{2 j}-\beta_{j} \cdot R_{m t}}{\sigma_{j}}\right)-\Phi_{1}\left(\frac{\alpha_{1 j}-\beta_{j} \cdot R_{m t}}{\sigma_{j}}\right)\right] \\
& \times \prod_{R_{2}} \frac{1}{\sigma_{j}} \phi\left[\frac{R_{j t}+\alpha_{2 j}-\beta_{j} \cdot R_{m t}}{\sigma_{j}}\right] .
\end{aligned}
$$

$R_{j t}$ and $R_{m t}$ denote the daily returns of the firm $j$ and of the market, respectively; $\beta_{j}$, is the firm j's return sensitivity to the market and $\sigma_{j}$ is the standard deviation of firm j's returns. $\Phi()$ is the distribution function of the standard normal distribution, and $\phi()$ is the standard normal density function. Finally $R_{1}\left(R_{2}\right)$ is the set of all days with non-zero returns and negative (positive) market returns and $\mathrm{R}_{0}$ is the set of all days with zero returns. We obtain convergence for $99.99 \%$ of our sample.

\section{Price Impact (Stoll 2000)}

We use the approach of Stoll (2000) to measure the price impact over the day in response to the daily trade imbalance. The price impact coefficient is $\beta_{1}$ in the following regression:

$$
\Delta P_{t}=\beta_{0}+\beta_{1} \cdot I_{t}+\beta_{2} \cdot I_{t-1}+e_{t}
$$

where $\Delta P_{t}$ is the daily change price, measured as $C_{t}-C_{t-1}\left(1+R_{I t}\right) ; C_{t}$ is the closing quote midpoint on day $t$ and $R_{I t}$ is the daily return on the S\&P 500 index. $I_{t}$ is the percentage imbalance on day $t$ and we calculate it as:

$$
I=\frac{\sum_{1}^{m} w_{i}^{A}-\sum_{1}^{n} w_{i}^{B}}{\sum_{1}^{m} w_{i}^{A}+\sum_{1}^{n} w_{i}^{B}} \cdot(100)
$$

where $w_{i}^{A}$ and $w_{i}^{B}$ are the share volume of transactions at the ask (sells) and transactions at the bid (buys), respectively. 


\section{Accruals Quality (Dechow and Dichev 2002, as amended by McNichols} 2002).

AccrualsQuality is the standard deviation of firm $j$ 's residuals $\left(v_{j, t}\right)$ calculated over a 5-year rolling window. The residuals are obtained from the cross-sectional regression, following Francis et. al (2005):

$$
\begin{aligned}
\frac{\text { TCA }_{j, t}}{\text { Assets }_{j, t}} & =\phi_{0, j}+\phi_{1, j} \frac{\text { FFO }_{j . t-1}}{\text { Assets }_{j, t}}+\phi_{2, j} \frac{C F O_{j, t}}{\text { Assets }_{j, t}} \\
& +\phi_{3, j} \frac{\operatorname{CFO}_{j, t+1}}{\text { Assets }_{j, t}}+\phi_{4, j} \frac{\Delta \operatorname{Re} v_{j, t}}{\text { Assets }_{j, t}}+\phi_{5, j} \frac{P P E_{j, t}}{\text { Assets }_{j, t}}+v_{j, t}
\end{aligned}
$$

where:

$T C A_{j, t}=$ firm $j$ 's total current accruals in year $t$

Assets $j, t_{,}=$firm j's average total assets in year $t$ and $t-1$

$C F O_{j, t}=$ firm $j$ 's cash flow from operations in year $t$

$\Delta \operatorname{Re} v_{j, t}=$ firm $j$ 's change in revenues (Compustat item \#12) between year $t-1$ and year $t$

$P P E_{j, t}=$ firm $j$ 's gross property, plant, and equipment (Compustat item \#7) in year $t$

\section{AQLoading (Ecker et al. 2006)}

AQLoading captures the sensitivity of firm $j$ 's returns to the accruals quality factor (AQFactor). The variable AQfactor is constructed following the same procedure as in Fama and French (1993). All firms are assigned to AccrualsQuality deciles on the first day of each month. This dynamic approach is possible due to differences in fiscal year ends of different companies. The AQfactor is then the difference in daily returns between the 4 bottom deciles and the 4 top deciles based on accruals quality. The estimation of AQLoading proceeds by including AQfactor as an additional factor into the classical Fama-French 3-factor framework:

$$
R_{j, t}-R_{F, t}=\alpha_{j, T}+\beta_{j, T}\left(R_{M, t}-R_{F, t}\right)+s_{j, T} S_{M B}+h_{j, T} H_{M L}+\text { AQLoading }_{j, T} \text { AQfactor }_{t}+\varepsilon_{j, T} .
$$




\section{References}

Aboody, David, and Baruch Lev, 2000, Information Asymmetry, R\&D, and Insider Gains, Journal of Finance 55, pp. 2747-2766

Admati, Anat R., and Paul Pfleiderer, 1988, A Theory of Intraday Patterns: Volume and Price Variability, Review of Financial Studies 1, pp. 3-40

Alexander, Gordon J., and Mark A. Peterson, 2007, An analysis of trade-size clustering and its relation to stealth trading, Journal of Financial Economics 84, pp. 435-471

Anand, Amber, and Sugato Chakravarty, 2007, Stealth Trading in Options Markets, Journal of Financial and Quantitative Analysis 42, pp. 167-188

Amihud, Yakov, 2002, Illiquidity and stock returns: cross-section and time-series effects, Journal of Financial Markets 5, pp. 31-56

Bainbridge, Stephen M., 1999, Insider Trading, Encyclopedia of Law and Economics 3, pp. $772-812$

Baker, Malcolm, and Jeffrey Wurgler, 2006, Investor Sentiment and the Cross-Section of Stock Returns, Journal of Finance 61, pp. 1645-1680

Barclay, Michael J., and Jerold B. Warner, 1993, Stealth Trading and Volatility: Which Trades Move Prices?, Journal of Financial Economics 34, pp. 281-305

Bessembinder, H., 2003, Issues in assessing trade execution costs, Journal of Financial Markets, pp. 233-257

Bettis, J. Carr; Jeffrey L. Coles, and Michael L. Lemmon, 2000, Corporate Policies Restricting Trading by Insiders, Journal of Financial Economics 57, pp. 191-220

Betzer, André, and Erik Theissen, 2009, Insider Trading and Corporate Governance: The Case of Germany, European Financial Management 15, pp. 402-429

Brennan, Michael J., and Marti Subrahmanyam, 1995, Investment Analysis and Price Formation in Securities Markets, Journal of Financial Economics 47, pp. 361-381

Brochet, Francois, 2008, Information Content of Insider Trades: Before and After the Sarbanes-Oxley Act, Working Paper, Harvard University, (May)

Brockman, Paul; Xiumin Martin, and Andy Puckett, 2008, Voluntary Disclosures and the Exercise of CEO Stock Options, Working Paper, University of Missouri, (July)

Chakravarty, Sugato, 2001, Stealth-Trading: Which Traders' Trades Move Stock Prices, Journal of Financial Economics 61, pp. 289-307

Chakravarty, Sugato; Petko S. Kalev, and Linh T. Pham, 2005, Stealth Trading in Volatile Markets, Working Paper, Purdue University, (October)

Cheng, Shijun; Venky Nagar, and Madhav V. Rajan, 2007, Insider Trades and Private Information: The Special Case of Delayed-Disclosure Trades, Review of Financial Studies 20, pp. 1833-1864 
Chiyachantana, Chiraphol N.; Pankah K. Jain; Christine X. Jiang, and Robert Wood, 2004, International Evidence on Institutional Trading Behavior and Price Impact, Journal of Finance 59, pp. 869-898

Chordia, Tarun; Richard Roll, and Avanidhar Subrahmanyam, 2001, Market Liquidity and Trading Activity, Journal of Finance 56, pp. 501-530

Cornett, M.M., Alan J. Marcus, and H. Tehranian, 2008, Corporate Governance and PayFor-Performance: The Impact of Earnings Management, Journal of Financial Economics 87, pp. 357-373

Dechow, Patricia M., and Ilia D. Dichev, 2002, The quality of accruals and earnings: The role of accrual estimation errors, The Accounting Review 77, pp. 35-59

Dechow, Patricia M., Richard G. Sloan, and Amy P. Sweeney, 1995, Detecting earnings management, The Accounting Review 70, pp. 193-225

Easley, David, Nicholas M. Kiefer, Maureen O'Hara, and Joseph B. Paperman, 1996, Liquidity, information, and infrequently traded stocks, The Journal of Finance 51, pp. 1405-1436

Ecker, Frank, Jennifer Francis, Irene Kim, Per M. Olsson, and Katherine Schipper, 2006, A returns-based representation of earnings quality, The Accounting Review 81, pp. 749-780

Fama, Eugene, and Kenneth French, 1993, Common risk factors in the returns on stocks and bonds, Journal of Financial Economics 33, pp. 3-56

Fernandes, Nuno, and Miguel A. Ferreira, 2009, Insider Trading Laws and Stock Price Informativeness, Review of Financial Studies 22, pp. 1845-1887

Fidrmuc, Jana P.; Marc Goergen, and Luc Renneboog, 2006, Insider Trading, News Releases, and Ownership Concentration, Journal of Finance 61, pp. 2931-2973

Fidrmuc, Jana P.; Korczak, Adriana and Korczak, Piotr, 2009, Insider Trading and Corporate Governance: International Evidence, Working Paper, (February)

Finnerty, Joseph E., 1976, Insiders and Market Efficiency, Journal of Finance 31, pp. 11411148

Forbes, 2009, Stealth Trading by Daniel Fisher, January 12

Francis J., R. LaFond, P. Olsson, and K. Schipper (2005), The Market Pricing of Accruals Quality, Journal of Accounting and Economics 39, pp. 295-327

Goyenko, Ruslan Y., Craig W. Holden, and Charles A. Trzcinka, 2009, Do liquidity measures measure liquidity?, Journal of Financial Economics 92, pp. 153-181

Henker, Thomas, and Jian-Xin Wang, 2006, On the Importance of Timing Specifications in Market Microstructure Research, Journal of Financial Markets 9, pp.162-179

Holden, Craig W., and Avanidhar Subrahmanyam, 1992, Long-lived private information and imperfect competition, The Journal of Finance 47, pp. 247-270

Huddart, Steven, John S. Hughes, and Carolyn B. Levine, 2001, Public disclosure and dissimulation of insider trades, Econometrica 69, pp. 665-681 
Jaffe, Jeffrey F., 1974, Special Information and Insider Trading, Journal of Business 47, pp. $410-428$

Jeng, Leslie A.; Andrew Metrick, and Richard Zeckhauser, 2003, Estimating the Returns to Insider Trading: A Performance-Evaluation Perspective, Review of Economics \& Statistics 85 , pp. 453-471

Jenter, Dirk, 2005, Market timing and managerial portfolio decisions, Journal of Finance 60, pp. 1903-1949

Jones, Jennifer J., 1991, Earnings management during import relief investigations, Journal of Accounting Research 29, pp. 193-228

Keim, Donald B., and Ananth Madhavan, 1995, Anatomy of the trading process empirical evidence on the behavior of institutional traders, Journal of Financial Economics 37, pp. 371398.

Klein, Daniel, and Ernst Maug, 2009, How do executives exercise their stock options?, Working Paper, University of Mannheim

Kyle, Albert S., 1985, Continuous Auctions and Insider Trading, Econometrica 53, pp. 13151335

Lakonishok, Josef, and Inmoo Lee, 2001, Are Insider Trades Informative?, Review of Financial Studies 14, pp. 79-111

Lee, Charles M. C.; Andrei Shleifer, and Richard H. Thaler, 1991, Investor Sentiment and the Closed-End Fund Puzzle, Journal of Finance 46, pp. 75-109

Lee, C., and M. Ready, 1991, Inferring trade direction from intraday data, Journal of Finance 46, pp. 733-746

Lemmon, Michael L., and Evgenia Portniaguina, 2006, Consumer Confidence and Asset Prices: Some Empirical Evidence, Review of Financial Studies 19, pp. 1499-1529

Lesmond, David A., 2005, Liquidity of Emerging Markets, Journal of Financial Economics 77, pp. 411-452

Lesmond, David A.; J. Ogden, and C. Trzcinka, 1999, A New Estimate of Transaction Costs, Review of Financial Studies 12, pp. 1113-1142

Lin, Ji-Chai, and John S. Howe, 1990, Insider Trading in the OTC Market, Journal of Finance 45, pp. 1273-1284

Lin, Ji-Chai, G. C. Sanger and G.G.Booth, 1995, Trade Size and Components of the Bid-Ask Spread, Review of Financial Studies 8, pp. 1153-1183

Lorie, James H., and Victor Niederhoffer, 1968, Predictive and Statistical Properties of Insider Trading, Journal of Law and Economics 11, pp. 35-53

Marin, Jose M., 2008, The Dog that Did not Bark: Insider Trading and Crashes, Journal of Finance 63, pp. 2429-2476

McNichols, Maureen F., 2002, The quality of accruals and earnings: The role of accrual estimation errors: Discussion, The Accounting Review 77, pp. 61-69 
Ofek, Eli, and David Yermack, 2000, Taking stock: Equity-based compensation and the evolution of managerial ownership, Journal of Finance 55, pp. 1367-1384

Pratt, Shannon P., and Charles W. DeVere, 1970, Relationship Between Insider Trading and Rates of Return for NYSE Common Stocks, 1960-1966, in: Lorie, James H., and Richard Brealey (editors): Modern Developments in Investment Management, New York (Prager Publishers)

Rogoff, Donald L., 1964, The Forecasting Properties of Insiders' Transactions, Journal of Finance 19, pp. 697-698

Rozeff, Michael S., and Mir A. Zaman, 1998, Overreaction and Insider Trading: Evidence from Growth and Value Portfolios, Journal of Finance 53, pp. 701-716

Scholes, Myron S., 1972, The Market for Securities: Substitution Versus Price Pressure and the Effects of Information on Share Prices, Journal of Business 45, pp. 179-211

Securities Industry News, 2006, Two JP Morgan Algos Eye Stealth Trading, Dark Liquidity by Katherine Heires, September 18

Seyhun, H. Nejat, 1986, Insiders' Profits, Costs of Trading, and Market Efficiency, Journal of Financial Economics 16, pp. 189-212

Seyhun, H. Nejat, 2000, Investment Intelligence from Insider Trading, Cambridge (MIT Press)

Stoll, Hans R., 2000, Friction, Journal of Finance, 46, pp. 1479-1514 


\section{Tables}

\section{Table 1: Sample design}

This table displays how our sample is constructed from raw Thomson Reuters Insider Filing database (IFDF) data to our final sample. We include all open market and private transactions in the IFDF database (Table One) between January 1, 1996 and December 31, 2006 in our initial dataset. We report the losses of observations after matching the IFDF data with CRSP, because of missing information, and consistency checks.

\begin{tabular}{lrrrr}
\hline & $\begin{array}{r}\text { Trans- } \\
\text { actions }\end{array}$ & $\mathbf{\%}$ & Firms & Insider \\
\hline IFDF data & $2,432,168$ & $100.0 \%$ & 16,522 & 137,806 \\
Observations lost because of: & 372,463 & $15.3 \%$ & & \\
Missing stock data on CRSP & 6,526 & $0.3 \%$ & & \\
Missing price or volume information on IFDF & 17,089 & $0.7 \%$ & & \\
Purchases and sales by the same insider on the same day & 116,316 & $4.8 \%$ & & \\
\# shares traded > total \# of shares traded at the same day & 64,706 & $2.7 \%$ & & \\
Insufficient data for event window or estimation period & $1,855,068$ & $76.3 \%$ & 9,563 & 97,205 \\
\hline Final sample & & & & \\
\hline
\end{tabular}

\section{Table 2: Variable definitions}

This table defines all variables used in this paper. Insider trading data are taken from IFDF, accounting data from Compustat, market data from CRSP and intraday transaction data from TAQ.

\begin{tabular}{|c|c|c|}
\hline Variable & Description & Source \\
\hline $\begin{array}{l}\text { Abnormal } \\
\text { Accruals }\end{array}$ & $\begin{array}{l}\text { Absolute value of abnormal accruals, obtained using the ap- } \\
\text { proach of Jones (1991) as modified by Dechow, Sloan, and } \\
\text { Sweeney (1995) }\end{array}$ & Compustat \\
\hline AccrualsQuality & $\begin{array}{l}\text { The measure of accruals quality of Dechow and Dichev } \\
\text { (2002), as amended by McNichols(2002). For estimation de- } \\
\text { tails, please refer to the Appendix . }\end{array}$ & Compustat \\
\hline $\begin{array}{l}\text { AfterEarn } \\
\text { Announce }\end{array}$ & $\begin{array}{l}1 \text { for all transactions executed in the } 14 \text { days after an earnings } \\
\text { announcement (if available), zero otherwise }\end{array}$ & Compustat \\
\hline Amihud & $\begin{array}{l}\text { Amihud's measure of illiquidity, defined as the ratio of the } \\
\text { daily absolute return to the dollar trading volume on that day } \\
\text { (Amihud, 2002) }\end{array}$ & CRSP \\
\hline AQLoading & $\begin{array}{l}\text { The measure of sensitivity of firm j's returns to the poor earn- } \\
\text { ings quality in year T (Ecker et al. 2006). For estimation de- } \\
\text { tails, please refer to the Appendix . }\end{array}$ & Compustat \\
\hline $\begin{array}{l}\text { BeforeEarn } \\
\text { Announce }\end{array}$ & $\begin{array}{l}1 \text { for all transactions executed in the } 14 \text { days before an earn- } \\
\text { ings announcement (if available), zero otherwise }\end{array}$ & Compustat \\
\hline
\end{tabular}




\begin{tabular}{|c|c|c|}
\hline Variable & Description & Source \\
\hline$\overline{C C I}$ & $\begin{array}{l}\text { Consumer confidence index based on a monthly survey of } \\
5,000 \text { U.S. households conducted for The Conference Board. It } \\
\text { averages five component indices, each of which is based on a } \\
\text { question regarding current or expected economic conditions }\end{array}$ & Data-stream \\
\hline CEO & 1 if trade is executed by the CEO, zero otherwise & IFDF \\
\hline Chairman & $\begin{array}{l}1 \text { if trade is executed by the chairman of the supervisory board, } \\
\text { who is not an officer, zero otherwise }\end{array}$ & IFDF \\
\hline Delay & Number of days between trading day and disclosure day & IFDF \\
\hline Director & $\begin{array}{l}1 \text { if trade is executed by a member of the board (not including } \\
\text { the chairman) who is not an officer, zero otherwise }\end{array}$ & IFDF \\
\hline EffectiveSpread & $\begin{array}{l}\text { Daily average of } 2\left|\mathrm{P}_{\mathrm{t}}-\mathrm{Q}_{\mathrm{t}}\right| / \mathrm{Q}_{\mathrm{t}} \text {, where } \mathrm{Q}_{\mathrm{t}} \text { is the quote midpoint } \\
\text { and } \mathrm{P}_{\mathrm{t}} \text { is the price at which a transaction is executed; observa- } \\
\text { tions with EffectiveSpread }>0.5 \text { are set to missing values }\end{array}$ & TAQ \\
\hline Gamma & $\begin{array}{l}\text { The order processing costs as a percentage of the effective } \\
\text { spread, based on Lin, Sanger, and Booth (1995). For estima- } \\
\text { tion details, please refer to the Appendix. Observations out of } \\
\text { range between } 0 \text { and } 1 \text { are set to missing values. }\end{array}$ & TAQ \\
\hline $\begin{array}{l}\text { Information- } \\
\text { Component }\end{array}$ & $\begin{array}{l}\text { Information component of the quoted spread based on } \\
\text { Stoll(2000) and defined as 1-TradedSpread/QuotedSpread. } \\
\text { For further calculation details, please refer to the Appendix . } \\
\text { Observations out of range between } 0 \text { and } 1 \text { are set to missing } \\
\text { values. }\end{array}$ & TAQ \\
\hline Lambda & $\begin{array}{l}\text { An adverse selection component of the effective spread, based } \\
\text { on Lin, Sanger, Booth (1995). For estimation details, please } \\
\text { refer to the Appendix . Observations out of range between } 0 \\
\text { and } 1 \text { are set to missing values. }\end{array}$ & TAQ \\
\hline LargeTrade & 1 if number of shares traded is $\geq 10,000$, zero otherwise & IFDF \\
\hline LogMarketCap & Natural logarithm of market capitalization & CRSP \\
\hline LOT & $\begin{array}{l}\text { The LOT measure of transaction costs, defined as roundtrip } \\
\text { proportional transaction costs from buying and selling; based } \\
\text { on Lesmond, Ogden, and Trzcinka (1999). For estimation de- } \\
\text { tails, please refer to the Appendix . }\end{array}$ & CRSP \\
\hline MarketCap & Market value of equity at the transaction date in million $€$ & CRSP \\
\hline MediumTrade & $\begin{array}{l}1 \text { if number of shares traded is } \geq 500 \text { and }<10,000 \text {, zero other- } \\
\text { wise }\end{array}$ & IFDF \\
\hline MultipleInsiders & $\begin{array}{l}1 \text { if more than one insider trades on the same day in the same } \\
\text { direction, zero otherwise }\end{array}$ & IFDF \\
\hline NumberTrans & $\begin{array}{l}\text { Number of transactions executed in one stealth trading se- } \\
\text { quence }\end{array}$ & IFDF \\
\hline Officer & 1 if trade is executed by an officer (not including the CEO) & IFDF \\
\hline
\end{tabular}




\begin{tabular}{|c|c|c|}
\hline Variable & Description & Source \\
\hline OtherInsider & $\begin{array}{l}1 \text { for all insiders who are not classified as an officer, chairman, } \\
\text { director, or CEO }\end{array}$ & IFDF \\
\hline PIN & $\begin{array}{l}\text { Probability of informed trading, calculated as the ratio of the } \\
\text { informed traders to the total number of traders on a particular } \\
\text { stock. First proposed by Easley et al. (1996). For estimation } \\
\text { details, please refer to the Appendix. }\end{array}$ & TAQ \\
\hline PriceImpact & $\begin{array}{l}\text { The measure of price impact as proposed by Stoll }(2000) \text { is a } \\
\text { coefficient from the regression of daily price change on the } \\
\text { daily trade imbalance between share volumes of purchases and } \\
\text { sales on day } t \text {. For estimation details, please refer to the Ap- } \\
\text { pendix. }\end{array}$ & TAQ \\
\hline Purchase & 1 if the transaction is a purchase, zero otherwise & IFDF \\
\hline PurchasesAR & $\begin{array}{l}\text { Abnormal return (market model) at the disclosure day for pur- } \\
\text { chases }\end{array}$ & IFDF \\
\hline$R \& D$ & Research and development expenditure / total assets & Compustat \\
\hline QuotedSpread & $\begin{array}{l}\text { Average daily quoted bid-ask spread, scaled by the quote mid- } \\
\text { point; observations with QuotedSpread }>0.5 \text { are set to missing } \\
\text { values }\end{array}$ & TAQ \\
\hline RunupCAR & $\begin{array}{l}\text { Cumulative abnormal return over a } 20 \text {-day event window } \\
(-20,-1) \text { ending one day before the trading day for sales and } \\
\text { purchases; CARs of sales are multiplied by }-1\end{array}$ & CRSP \\
\hline Sales & Sales of the last calendar year in million $€$ & Compustat \\
\hline SalesAR & Abnormal return (market model) at the disclosure day for sales & CRSP \\
\hline Sentiment & $\begin{array}{l}\text { Monthly sentiment index, taken from Baker and Wurgler } \\
\text { (2007); based on first principal component of six (standard- } \\
\text { ized) sentiment proxies over 1966-2005 data. }\end{array}$ & $\begin{array}{l}\text { Baker and } \\
\text { Wurgler }\end{array}$ \\
\hline ShortSide & $\begin{array}{l}1 \text { for purchases if StockTercile }=3 ; 1 \text { for sales if StockTer- } \\
\text { cile }=1 \text {; zero otherwise }\end{array}$ & CRSP \\
\hline SmallTrade & 1 if number of shares traded $<500$, zero otherwise & IFDF \\
\hline SOX & 1 if trade is executed after August 28,2002 , zero otherwise & IFDF \\
\hline Stake & Number of shares traded by insider / total number of shares & $\begin{array}{l}\text { IFDF/ } \\
\text { CRSP }\end{array}$ \\
\hline StakeDecile & $\begin{array}{l}\text { Decile of the Stake traded in the transaction of all sample } \\
\text { transactions, ranging between } 1 \text { (lowest) and } 10 \text { (highest) }\end{array}$ & $\begin{array}{l}\text { IFDF/ } \\
\text { CRSP }\end{array}$ \\
\hline Stealth & $\begin{array}{l}1 \text { for all transactions of a trading sequence, where all trades } \\
\text { are in the same direction. The last transaction is always before } \\
\text { or on the day the first transaction is disclosed or within } 40 \\
\text { days of the first transaction, whichever is earlier. }\end{array}$ & IFDF \\
\hline
\end{tabular}




\begin{tabular}{lll}
\hline Variable & Description & Source \\
\hline StockTercile & $\begin{array}{l}\text { Tercile of the firm's stock return in the previous calendar } \\
\text { month of all sample firms' stock returns, ranging from 1 (low- } \\
\text { est) to 3 (highest) }\end{array}$ & CRSP \\
Theta & $\begin{array}{l}\text { The measure of order persistence based on Lin, Sanger and } \\
\text { Booth (1995). For estimation details, please refer to the Ap- } \\
\text { pendix . Observations out of range between 0 and 1 are set to } \\
\\
\text { missing values. }\end{array}$ & TAQ \\
& $\begin{array}{l}\text { Total number of shares traded on the transaction day / total } \\
\text { number of shares outstanding }\end{array}$ & CRSP \\
Volatility & $\begin{array}{l}\text { Annualized standard deviation of daily stock returns over the } \\
\text { preceding calendar month }\end{array}$ & CRSP \\
Volume & Volume of the transaction in thousand U.S. \$ & IFDF \\
\hline
\end{tabular}

\section{Table 3: Summary statistics}

This table displays descriptive statistics for all variables used in our analysis. Insider trading data are taken from IFDF, accounting data from Compustat, market data from CRSP and intraday data from TAQ.

\begin{tabular}{lrrrrrrrr}
\hline \multicolumn{1}{c}{ Variable } & $\mathbf{N}$ & Mean & Median & $\begin{array}{c}\text { Standard } \\
\text { deviation }\end{array}$ & Min & Max & $\begin{array}{c}\text { Skew- } \\
\text { ness }\end{array}$ & Kurtosis \\
\hline AbnormalAccruals & $1,128,807$ & 0.068 & 0.046 & 0.089 & 0.000 & 1.914 & 6.8 & 97.5 \\
AccrualsQuality & $1,141,852$ & 0.063 & 0.047 & 0.050 & 0.001 & 0.727 & 2.7 & 16.5 \\
AfterEarnAnnounce & $1,855,068$ & 0.200 & 0 & 0.400 & 0 & 1 & 1.5 & 3.2 \\
Amihud & $1,854,967$ & 0.700 & 0.004 & 9.108 & 0.000 & $1,944.8$ & 71.9 & $9,028.5$ \\
AQLoading & $1,838,259$ & 0.307 & 0.081 & 1.230 & -34.266 & 64.972 & 1.2 & 34.2 \\
BeforeEarnAnnounce & $1,855,068$ & 0.045 & 0 & 0.206 & 0 & 1 & 4.4 & 20.5 \\
CCI & $1,855,068$ & 107.117 & 105.100 & 17.782 & 61.4 & 144.7 & 0.3 & 2.6 \\
CEO & $1,855,068$ & 0.177 & 0 & 0.382 & 0 & 1 & 1.7 & 3.9 \\
Chairman & $1,855,068$ & 0.037 & 0 & 0.189 & 0 & 1 & 4.9 & 25.1 \\
Delay & $1,855,068$ & 21.010 & 4 & 74.931 & 0 & 3,635 & 15.9 & 405.5 \\
Director & $1,855,068$ & 0.244 & 0 & 0.430 & 0 & 1 & 1.2 & 2.4 \\
EffectiveSpread & $1,714,399$ & $0.85 \%$ & $0.34 \%$ & $1.50 \%$ & $0.00 \%$ & $50.00 \%$ & 5.9 & 65.5 \\
Gamma & 844,946 & 0.020 & 0.000 & 0.123 & 0.000 & 1.000 & 7.2 & 53.9 \\
InformationComponent & $1,247,972$ & 0.658 & 0.726 & 0.266 & 0.000 & 1.0 & -0.7 & 2.4 \\
Lambda & $1,665,297$ & 0.400 & 0.386 & 0.271 & 0.000 & 1.000 & 0.2 & 1.9 \\
LOT & $1,833,471$ & 0.021 & 0.012 & 0.030 & -0.041 & 1.804 & 4.6 & 52.4 \\
MarketCap (in million $\$$ \$) & $1,855,068$ & 8,521 & 761 & 30,968 & 0.2 & 571,816 & 7.5 & 75.5 \\
MultipleInsiders & $1,855,068$ & 0.400 & 0 & 0.490 & 0 & 1 & 0.4 & 1.2 \\
NumberTrans & 230,223 & 7.003 & 3 & 18.880 & 2 & 1744 & 32.7 & 2,047 \\
Officer & $1,855,068$ & 0.379 & 0 & 0.485 & 0 & 1 & 0.5 & 1.2 \\
OtherInsider & $1,855,068$ & 0.162 & 0 & 0.369 & 0 & 1 & 1.8 & 4.4 \\
\hline
\end{tabular}




\begin{tabular}{lrrrrrrrr}
\hline \multicolumn{1}{c}{ Variable } & $\mathbf{N}$ & Mean & Median & $\begin{array}{c}\text { Standard } \\
\text { deviation }\end{array}$ & Min & Max & $\begin{array}{c}\text { Skew- } \\
\text { ness }\end{array}$ & Kurtosis \\
\hline PIN & $1,670,900$ & 0.154 & 0.139 & 0.087 & 0 & 1 & 1.5 & 9.8 \\
PriceImpact & $1,695,900$ & 0.037 & 0.005 & 0.431 & -65.554 & 207 & 296.9 & 137,901 \\
Purchase & $1,855,068$ & 0.209 & 0 & 0.407 & 0 & 1 & 1.4 & 3.0 \\
PurchasesAR & 147,357 & 0.002 & 0.000 & 0.044 & -0.514 & 1.012 & 1.9 & 27.3 \\
QuarterlyReport & $1,770,028$ & 0.999 & 1 & 0.038 & 0 & 1 & -26.4 & 699.8 \\
QuotedSpread & $1,727,517$ & $1.41 \%$ & $0.66 \%$ & $2.19 \%$ & $0.02 \%$ & $40.00 \%$ & 4.6 & 36.7 \\
R\&D & $1,770,028$ & 0.047 & 0.000 & 0.096 & 0.000 & 3.956 & 9.4 & 239.5 \\
RunupCAR & 473,002 & -0.030 & -0.019 & 0.181 & -8.928 & 3.130 & -2.6 & 66.1 \\
Sales (in million $\$$ ) & $1,736,672$ & 3,371 & 466 & 12,962 & 0 & 345,977 & 13.3 & 244.5 \\
SalesAR & 325,645 & -0.001 & -0.002 & 0.034 & -0.692 & 1.293 & 1.8 & 55.3 \\
Sentiment & $1,516,826$ & 0.105 & -0.070 & 0.654 & -0.830 & 2.500 & 1.1 & 4.1 \\
ShortSide & $1,855,068$ & 0.233 & 0 & 0.423 & 0 & 1 & 1.3 & 2.6 \\
SOX & $1,855,068$ & 0.588 & 1 & 0.492 & 0 & 1 & -0.4 & 1.1 \\
Stake & $1,855,068$ & $0.036 \%$ & $0.004 \%$ & $0.234 \%$ & $0.000 \%$ & $65.804 \%$ & 56.9 & $7,212.3$ \\
Stealth & $1,855,068$ & 0.869 & 1 & 0.337 & 0 & 1 & -2.2 & 5.8 \\
StockTercile & $1,836,305$ & 2.185 & 2 & 0.820 & 1 & 3 & -0.4 & 1.6 \\
Turnover & $1,855,068$ & 0.017 & 0.007 & 0.071 & 0.000 & 14.228 & 39.9 & $2,915.2$ \\
Volatility & $1,838,268$ & 0.517 & 0.409 & 0.405 & 0.011 & 15.589 & 4.3 & 53.7 \\
Volume (in thousend $\$$ ) & $1,855,068$ & 301 & 31 & 3,289 & 0 & 883,742 & $167.041,278.2$ \\
\hline
\end{tabular}




\section{Table 4: Existence of stealth trading \\ Panel A: Univariate analysis}

This table displays the percentage of transactions which are followed by a transaction in the same direction (separated for purchases and sales). Please note that the total number of transactions is reduced and the percentage of sales is different compared to the original sample because the first transaction of each individual insider in each firm can only be used as benchmark for the next transaction by the insider in the respective firm. The $\mathrm{Chi}^{2}{ }^{2}$ test on independence and the Fisher exact test are based on the contingency table expressing the relationship between sales and purchases conditional on the prior direction of trade.

\begin{tabular}{lrrrr}
\hline & $\mathbf{( 1 )}$ & $\mathbf{( 2 )}$ & $\mathbf{( 3 )}$ & $\mathbf{( 4 )}$ \\
\hline Observations & $\begin{array}{c}\text { All without } \\
\text { first for each } \\
\text { person }\end{array}$ & $\begin{array}{c}\text { Only within } \\
\text { 183 days of } \\
\text { each other }\end{array}$ & $\begin{array}{r}\text { Only within } \\
\text { 40 days of } \\
\text { each other }\end{array}$ & $\begin{array}{r}\text { Only within } \\
\text { 2 days of } \\
\text { each other }\end{array}$ \\
\hline Same Direction & & & & \\
$\quad$ Sales & $98.67 \%$ & $99.65 \%$ & $99.84 \%$ & $99.97 \%$ \\
$\quad$ Purchases & $96.82 \%$ & $98.66 \%$ & $99.36 \%$ & $99.85 \%$ \\
\% Sales / Total & $80.51 \%$ & $81.03 \%$ & $82.05 \%$ & $84.08 \%$ \\
\# of observations & $1,737,495$ & $1,628,811$ & $1,513,281$ & $1,283,510$ \\
Chi ${ }^{2}$-test (p-value) & $0.00 \%$ & $0.00 \%$ & $0.00 \%$ & $0.00 \%$ \\
Fisher exact test (p-value) & $0.00 \%$ & $0.00 \%$ & $0.00 \%$ & $0.00 \%$ \\
\hline
\end{tabular}

Panel B: Probit regressions

The table presents results for Probit regressions with Purchase as dependent variable. See Table 2 for a definition of all variables. For each independent variable, the table displays the marginal effects (evaluated at the mean of the independent variables) and in parentheses, the t-statistic of the two-sided t-test for a coefficient equal to zero. In all regressions t-statistics are based on heteroscedasticity-robust standard errors. Additionally, we report McFadden's $\mathrm{R}^{2}$ and the p-values of the F-test with the null-hypothesis of the coefficient of LagPurchase being equal to its unconditional mean.

\begin{tabular}{|c|c|c|c|c|c|c|}
\hline & (1) & (2) & (3) & (4) & (5) & (6) \\
\hline LagPurchase & $\begin{array}{c}0.9387 \\
(814.48)\end{array}$ & $\begin{array}{c}0.9364 \\
(807.27)\end{array}$ & $\begin{array}{c}0.9350 \\
(757.35)\end{array}$ & $\begin{array}{c}0.9370 \\
(786.28)\end{array}$ & $\begin{array}{c}0.9387 \\
(814.78)\end{array}$ & $\begin{array}{c}0.9324 \\
(728.77)\end{array}$ \\
\hline $\mathrm{CCI}$ & & $\begin{array}{l}0.0006 \\
(37.90)\end{array}$ & & & & $\begin{array}{l}0.0005 \\
(25.08)\end{array}$ \\
\hline Sentiment & & & $\begin{array}{l}0.0161 \\
(29.70)\end{array}$ & & & $\begin{array}{l}0.0043 \\
(6.47)\end{array}$ \\
\hline StockTercile & & & & $\begin{array}{l}-0.0250 \\
(-79.56)\end{array}$ & & $\begin{array}{l}-0.0320 \\
(-77.15)\end{array}$ \\
\hline RunupCAR & & & & & $\begin{array}{r}-0.0018 \\
(-1.19)\end{array}$ & $\begin{array}{l}0.0057 \\
(3.12) \\
\end{array}$ \\
\hline Observations & $1,737,495$ & $1,737,495$ & $1,405,871$ & $1,720,191$ & $1,737,495$ & $1,392,727$ \\
\hline Pseudo R ${ }^{2}$ & 0.842 & 0.843 & 0.834 & 0.846 & 0.842 & 0.838 \\
\hline LagPurchase $=0.195$ & $(0.0 \%)$ & $(0.0 \%)$ & $(0.0 \%)$ & $(0.0 \%)$ & $(0.0 \%)$ & $(0.0 \%)$ \\
\hline
\end{tabular}




\section{Table 5: Summary statistics: non-stealth vs. stealth trades}

This table compares descriptive statistics for 8 variables, which we use in our analysis for stealth and non-stealth transactions. See Table 2 for a definition of all variables. For each variable, the table displays the $p$-value of the two-sided t-test on the equality of means and the p-value of the Wilcoxon rank-sum test.

\begin{tabular}{|c|c|c|c|c|c|c|c|c|}
\hline \multirow{2}{*}{ Variable } & $\mathbf{N}$ & Mean & Median & $\mathbf{N}$ & Mean & Median & T-test & $\begin{array}{l}\text { Wilcox- } \\
\text { on test }\end{array}$ \\
\hline & \multicolumn{3}{|c|}{ Non-stealth trades } & \multicolumn{3}{|c|}{ Single stealth trades } & & \\
\hline SmallTrade & 242,779 & 0.164 & 0 & $1,612,289$ & 0.284 & 0 & $(0.0 \%)$ & $(0.0 \%)$ \\
\hline MediumTrade & 242,779 & 0.547 & 1 & $1,612,289$ & 0.543 & 1 & $(0.1 \%)$ & $(0.1 \%)$ \\
\hline LargeTrade & 242,779 & 0.289 & 0 & $1,612,289$ & 0.173 & 0 & $(0.0 \%)$ & $(0.0 \%)$ \\
\hline Volume & 242,779 & 480.6 & 56.9 & $1,612,289$ & 274.3 & 28.9 & $(0.0 \%)$ & $(0.0 \%)$ \\
\hline Stake & 242,779 & $0.066 \%$ & $0.011 \%$ & $1,612,289$ & $0.031 \%$ & $0.004 \%$ & $(0.0 \%)$ & $(0.0 \%)$ \\
\hline \multirow[t]{2}{*}{ Purchase } & 242,779 & 0.369 & 0 & $1,612,289$ & 0.185 & 0 & $(0.0 \%)$ & $(0.0 \%)$ \\
\hline & \multicolumn{3}{|c|}{ Non-stealth trades } & \multicolumn{3}{|c|}{ Aggregated stealth trades } & & \\
\hline SmallTrade & 242,779 & 0.164 & 0 & 230,223 & 0.038 & 0 & $(0.0 \%)$ & $(0.0 \%)$ \\
\hline MediumTrade & 242,779 & 0.547 & 1 & 230,223 & 0.354 & 0 & $(0.0 \%)$ & $(0.0 \%)$ \\
\hline LargeTrade & 242,779 & 0.289 & 0 & 230,223 & 0.608 & 1 & $(0.0 \%)$ & $(0.0 \%)$ \\
\hline Volume & 242,779 & 480.6 & 56.9 & 230,223 & $1,920.8$ & 261.4 & $(0.0 \%)$ & $(0.0 \%)$ \\
\hline Stake & 242,779 & $0.066 \%$ & $0.011 \%$ & 230,223 & $0.219 \%$ & $0.049 \%$ & $(0.0 \%)$ & $(0.0 \%)$ \\
\hline Purchase & 242,779 & 0.369 & 0 & 230,223 & 0.251 & 0 & $(0.0 \%)$ & $(0.0 \%)$ \\
\hline PurchasesAR & 89,632 & 0.002 & 0.000 & 57,725 & 0.003 & 0.000 & $(0.5 \%)$ & $(51.4 \%)$ \\
\hline SalesAR & 153,147 & -0.001 & -0.001 & 172,498 & -0.001 & -0.002 & $(93.7 \%)$ & $(0.0 \%)$ \\
\hline
\end{tabular}




\section{Table 6: Determinants of stealth trading}

The table presents results for Probit regressions with Stealth as the dependent variable. See Table 2 for a definition of all variables. For each independent variable, the table displays the marginal effects (evaluated at the mean of the independent variables) and, in parentheses, the t-statistic of the two-sided t-test with a null-hypothesis of a coefficient equaling zero. In all regressions t-statistics are based on heteroscedasticity-robust standard errors. We also report McFadden's $\mathrm{R}^{2}$. All regressions include calendar year dummies and industry dummies. The economic significance is calculated based on the marginal effects from model (3). For AccrualsQuality the economic significance is calculated based on its marginal effect from model (6) 


\begin{tabular}{|c|c|c|c|c|c|c|c|}
\hline & (1) & (2) & (3) & (4) & (5) & (6) & $\begin{array}{c}\text { Economic } \\
\text { significance }\end{array}$ \\
\hline \multirow{2}{*}{$\underset{\text { StakeDecile }}{ }$} & 0.0875 & 0.0876 & 0.0876 & 0.0907 & 0.0908 & 0.0908 & \multirow[t]{2}{*}{0.0876} \\
\hline & (192.1) & $(192.2)$ & (192.2) & (153.5) & (153.5) & $(153.6)$ & \\
\hline \multirow[t]{2}{*}{ CEO } & 0.0156 & 0.0157 & 0.0156 & 0.0050 & 0.0050 & 0.0049 & \multirow[t]{2}{*}{0.0156} \\
\hline & $(4.48)$ & $(4.51)$ & $(4.48)$ & (1.14) & (1.13) & $(1.11)$ & \\
\hline \multirow{4}{*}{$\begin{array}{l}\text { Nofficer } \\
\text { on } \\
0 \\
0\end{array}$} & -0.0128 & -0.0127 & -0.0128 & -0.0220 & -0.0219 & -0.0220 & \multirow[t]{2}{*}{-0.0128} \\
\hline & $(-5.42)$ & $(-5.36)$ & $(-5.40)$ & $(-7.15)$ & $(-7.12)$ & $(-7.15)$ & \\
\hline & 0.0069 & 0.0066 & 0.0065 & -0.0092 & -0.0094 & -0.0096 & \multirow[t]{2}{*}{0.0065} \\
\hline & (1.08) & $(1.04)$ & $(1.02)$ & $(-1.14)$ & $(-1.17)$ & $(-1.19)$ & \\
\hline \multirow[t]{2}{*}{ OtherInsider } & 0.0756 & 0.0753 & 0.0754 & 0.0661 & 0.0658 & 0.0659 & \multirow[t]{2}{*}{0.0754} \\
\hline & (18.61) & $(18.55)$ & (18.56) & (12.61) & $(12.56)$ & $(12.57)$ & \\
\hline \multirow{2}{*}{$\begin{array}{l}\text { m Purchase } \\
\text { I }\end{array}$} & 0.0169 & 0.0162 & 0.0160 & 0.0092 & 0.0085 & 0.0082 & \multirow[t]{2}{*}{0.0160} \\
\hline & $(6.33)$ & $(6.05)$ & $(5.99)$ & $(2.60)$ & $(2.38)$ & $(2.30)$ & \\
\hline \multirow[t]{2}{*}{ AccrualsQuality } & & & & 0.0518 & 0.0522 & 0.0519 & \multirow[t]{2}{*}{0.0026} \\
\hline & & & & $(1.70)$ & $(1.71)$ & $(1.70)$ & \\
\hline \multirow[t]{2}{*}{ AQLoading } & 0.0017 & 0.0018 & 0.0017 & & & & \multirow[t]{2}{*}{0.0021} \\
\hline & $(1.84)$ & $(1.92)$ & $(1.89)$ & & & & \\
\hline \multirow[t]{2}{*}{ InformationComponent } & 0.0073 & -0.0003 & & 0.0056 & -0.0021 & & \multirow{4}{*}{0.0000} \\
\hline & $(1.80)$ & $(-0.06)$ & & $(1.06)$ & $(-0.39)$ & & \\
\hline \multirow{2}{*}{$\begin{array}{l}+ \\
\tilde{\omega} \\
\tilde{d}\end{array}$} & -0.0009 & 0.0007 & 0.0004 & 0.0327 & 0.0345 & 0.0339 & \\
\hline & $(-0.06)$ & $(0.06)$ & $(0.03)$ & $(1.74)$ & $(1.83)$ & $(1.81)$ & \\
\hline R\&D & 0.0572 & 0.0606 & 0.0602 & 0.0665 & 0.0703 & 0.0700 & \multirow{2}{*}{0.0058} \\
\hline & $(4.47)$ & (4.73) & $(4.70)$ & $(4.12)$ & $(4.35)$ & $(4.34)$ & \\
\hline \multirow[t]{2}{*}{ I Volatility } & 0.0139 & 0.0150 & 0.0142 & 0.0101 & 0.0120 & 0.0110 & \multirow[t]{2}{*}{0.0057} \\
\hline & $(3.82)$ & $(4.17)$ & $(3.92)$ & $(2.09)$ & $(2.49)$ & $(2.29)$ & \\
\hline BeforeEarnAnnounce & 0.0155 & 0.0156 & 0.0156 & 0.0139 & 0.0141 & 0.0141 & 0.0156 \\
\hline & $(3.19)$ & $(3.21)$ & $(3.20)$ & $(2.20)$ & $(2.23)$ & $(2.22)$ & \\
\hline AfterEarnAnnounce & 0.0134 & 0.0133 & 0.0133 & 0.0119 & 0.0119 & 0.0119 & 0.0133 \\
\hline & $(5.69)$ & $(5.65)$ & $(5.66)$ & $(3.96)$ & $(3.95)$ & $(3.96)$ & \\
\hline EffectiveSpread & 1.0754 & & & 1.2204 & & & \\
\hline & $(12.19)$ & & & $(10.06)$ & & & \\
\hline$\stackrel{n}{\infty}$ QuotedSpread & & 0.7927 & & & 0.8403 & & \\
\hline & & $(13.66)$ & & & (10.93) & & \\
\hline 宽 InfoComp*QuotSpread & & & 0.7235 & & & 0.7522 & 0.0114 \\
\hline & & & $(10.68)$ & & & $(8.57)$ & \\
\hline (1-InfoComp)*QuotSpread & & & 0.9772 & & & 1.0964 & 0.0100 \\
\hline & & & $(8.58)$ & & & $(6.83)$ & \\
\hline ShortSide & 0.0119 & 0.0118 & 0.0118 & 0.0137 & 0.0135 & 0.0135 & 0.0118 \\
\hline 0 & $(5.06)$ & $(4.98)$ & $(4.98)$ & $(4.42)$ & $(4.34)$ & $(4.34)$ & \\
\hline İं MultipleInsiders & 0.0526 & 0.0528 & 0.0528 & 0.0537 & 0.05384 & 0.0539 & 0.0528 \\
\hline & $(26.28)$ & $(26.37)$ & $(26.39)$ & $(20.77)$ & $(20.81)$ & $(20.83)$ & \\
\hline LogMarketCap & 0.0498 & 0.0504 & 0.0506 & 0.0520 & 0.0524 & 0.0526 & 0.1064 \\
\hline & $(59.90)$ & $(60.27)$ & $(60.63)$ & $(47.82)$ & $(48.06)$ & $(48.25)$ & \\
\hline SOX & -0.0382 & -0.0394 & -0.0389 & -0.0327 & -0.0336 & -0.0332 & -0.0389 \\
\hline & $(-5.19)$ & $(-5.35)$ & $(-5.29)$ & $(-3.58)$ & $(-3.69)$ & $(-3.65)$ & \\
\hline Observations & 307,546 & 307,540 & 307,540 & 186,979 & 186,976 & 186,976 & \\
\hline Pseudo $\mathrm{R}^{2}$ & 0.148 & 0.148 & 0.148 & 0.153 & 0.153 & 0.153 & \\
\hline Year and industry dummies & Yes & Yes & Yes & Yes & Yes & Yes & \\
\hline
\end{tabular}




\section{Table 7: Comparisons of explanatory power}

The table presents results for the comparison of the explanatory power of our different hypotheses and groups of hypotheses. In each column the log likelihood of the restricted model (without the variables associated with the respective hypothesis), the Likelihood ratio test statistic ( $\mathrm{Chi}^{2}$ test) and the $1 \%$ cut-off level for this test are reported for Probit regressions with Stealth as the dependent variable. Each column also reports the $\mathrm{R}^{2}$ of the restricted model and the partial $\mathrm{R}^{2}$, which is defined as the difference of the $\mathrm{R}^{2}$ of the full model and the restricted model, for OLS regressions with Stealth as the dependent variable. The full model includes CEO, Officer, Chairman, OtherInsider, Purchase, AQLoading, PIN, R\&D, Volatility, BeforeEarnAnnounce, AfterEarnAnnounce, StakeDecile, InfoComp*QuotSpread, (1-InfoComp)*QuotSpread, ShortSide, MultipleInsiders, LogMarketCap, $S O X$, year and industry dummies. See Table 2 for a definition of all variables.

\section{Panel A: Pooled sample}

The log likelihood of the full Probit model (pooled sample) is $-181,373$ and the $\mathrm{R}^{2}$ of the full OLS model is 0.1900 .

\begin{tabular}{cccc}
\hline Hypothesis & \multicolumn{2}{c}{ Information } & Liquidity \\
\hline & $\begin{array}{c}\text { predicted } \\
\text { sign }\end{array}$ & $\begin{array}{c}\text { opposite } \\
\text { sign }\end{array}$ & \\
\hline & $(1)$ & $(2)$ & $(3)$ \\
\hline Log Likelihood (restricted) & $-181,494$ & $-181,636$ & $-181,764$ \\
Ð Chi ${ }^{2}$ test & 242 & 526 & 782 \\
\& $1 \%$ cut-off level & 21.67 & 11.34 & 11.34 \\
\& R-Squared (restricted) & 0.1884 & 0.1879 & 0.1869 \\
Partial R-Squared & 0.0016 & 0.0021 & 0.0031 \\
\hline
\end{tabular}

\section{Panel B: pre/post-SOX}

The log likelihood of the full Probit model for pre-SOX (post-SOX) sub sample is $-78,780(-101,129)$ and the $\mathrm{R}^{2}$ of the full OLS model is $0.2364(0.1643)$, respectively.

\begin{tabular}{|c|c|c|c|}
\hline \multirow[t]{2}{*}{ Hypothesis } & \multicolumn{2}{|c|}{ Information } & \multirow[t]{2}{*}{ Liquidity } \\
\hline & $\begin{array}{l}\text { predicted } \\
\text { sign }\end{array}$ & $\begin{array}{l}\text { opposite } \\
\text { sign }\end{array}$ & \\
\hline & (1) & $(2)$ & $(3)$ \\
\hline Log Likelihood (restricted) & $-78,937$ & $-78,928$ & $-79,267$ \\
\hline $\mathrm{Chi}^{2}$ test & 313 & 295 & 973 \\
\hline is $1 \%$ cut-off level & 21.67 & 11.34 & 11.34 \\
\hline R-Squared (restricted) & 0.2330 & 0.2333 & 0.2292 \\
\hline Partial R-Squared & 0.0034 & 0.0031 & 0.0072 \\
\hline Log Likelihood (restricted) & $-101,185$ & $-101,271$ & $-101,187$ \\
\hline $\mathrm{Chi}^{2}$ test & 111 & 283 & 115 \\
\hline 竞 $1 \%$ cut-off level & 18.48 & 15.09 & 11.34 \\
\hline$\AA$ R-Squared (restricted) & 0.1621 & 0.1614 & 0.1620 \\
\hline Partial R-Squared & 0.0022 & 0.0029 & 0.0023 \\
\hline
\end{tabular}




\section{Panel C: NYSE/NASDAQ}

The log likelihood of the full Probit model for NYSE (NASDAQ) sub sample is $-77,694(-99,546)$ and the $\mathrm{R}^{2}$ of the full OLS model is $0.1966(0.1951)$, respectively.

\begin{tabular}{lccc}
\hline \multicolumn{1}{c}{ Hypothesis } & \multicolumn{2}{c}{ Information } & Liquidity \\
\hline & $\begin{array}{c}\text { predicted } \\
\text { sign }\end{array}$ & $\begin{array}{c}\text { opposite } \\
\text { sign }\end{array}$ & \\
\hline & $(1)$ & $(2)$ & $(3)$ \\
\hline Log Likelihood (restricted) & $-77,728$ & $-77,782$ & $-77,868$ \\
데 Chi ${ }^{2}$ test & 68 & 176 & 348 \\
乙 $1 \%$ cut-off level & 21.67 & 11.34 & 11.34 \\
Z-Squared (restricted) & 0.1943 & 0.1938 & 0.1925 \\
Partial R-Squared & 0.0023 & 0.0028 & 0.0041 \\
\hline Log Likelihood (restricted) & $-99,669$ & $-99,717$ & $-99,741$ \\
O Chi ${ }^{2}$ test & 245 & 341 & 389 \\
Oे $1 \%$ cut-off level & 20.09 & 13.28 & 11.34 \\
¿ R-Squared (restricted) & 0.1925 & 0.1923 & 0.1917 \\
Partial R-Squared & 0.0026 & 0.0028 & 0.0034 \\
\hline
\end{tabular}




\section{Table 8: Sample splits: pre/post-SOX and NYSE/NASDAQ}

The table presents results for Probit regressions with Stealth as dependent variable. See Table 2 for a definition of all variables. For each independent variable, the table displays the marginal effects (evaluated at the mean of the independent variables) and, in parentheses, the t-statistic for the two-sided t-test for a coefficient equal to zero. In all regressions t-values are based on heteroscedasticity-robust standard errors. We also report McFadden's $\mathrm{R}^{2}$. 


\begin{tabular}{|c|c|c|c|c|c|c|c|}
\hline & & Pre-SOX & Post-SOX & $\begin{array}{c}\text { High } \\
\text { spread }\end{array}$ & $\begin{array}{c}\text { Low } \\
\text { spread }\end{array}$ & NYSE & NASDAQ \\
\hline & & (1) & (2) & (3) & (4) & (5) & (6) \\
\hline- & StakeDecile & 0.0977 & 0.0802 & 0.0896 & 0.0871 & 0.0894 & 0.0870 \\
\hline$\dot{I}$ & & (139.7) & (130.1) & (139.0) & (132.3) & $(124.0)$ & $(142.3)$ \\
\hline & $\mathrm{CEO}$ & 0.0126 & 0.0127 & 0.0202 & 0.0070 & 0.0092 & 0.0205 \\
\hline & & $(2.27)$ & $(2.81)$ & $(4.18)$ & $(1.38)$ & $(1.61)$ & $(4.61)$ \\
\hline$N_{\infty}$ & Officer & 0.0093 & -0.0266 & -0.0084 & -0.0199 & 0.0018 & -0.0207 \\
\hline$\overline{\mathscr{g}}$ & & $(2.65)$ & $(-8.21)$ & $(-2.49)$ & $(-5.89)$ & $(0.49)$ & $(-6.53)$ \\
\hline 宽 & Chairman & 0.0290 & -0.0206 & 0.0264 & -0.0210 & 0.0162 & 0.0002 \\
\hline & & (3.13) & $(-2.31)$ & $(2.97)$ & $(-2.28)$ & $(1.56)$ & $(0.03)$ \\
\hline & OtherInsider & 0.0994 & 0.0590 & 0.0845 & 0.0530 & 0.0809 & 0.0732 \\
\hline & & $(16.00)$ & $(10.76)$ & (16.38) & $(7.85)$ & (12.32) & (13.73) \\
\hline$m$ & Purchase & 0.0520 & -0.0114 & 0.0298 & -0.0101 & 0.0033 & 0.0279 \\
\hline$\dot{I}$ & & (13.75) & $(-2.90)$ & $(8.66)$ & $(-2.28)$ & $(0.80)$ & (7.67) \\
\hline & AQLoading & 0.0021 & 0.0013 & 0.0020 & -0.0015 & 0.0025 & 0.0003 \\
\hline & & $(1.46)$ & $(1.01)$ & $(1.73)$ & $(-0.89)$ & $(1.24)$ & $(0.28)$ \\
\hline & PIN & -0.0277 & 0.0347 & -0.0327 & 0.0370 & 0.0163 & -0.0205 \\
\hline & & $(-1.62)$ & $(1.58)$ & $(-2.09)$ & (1.39) & $(0.70)$ & $(-1.21)$ \\
\hline$\underset{n}{+}$ & $\mathrm{R} \& \mathrm{D}$ & 0.0540 & 0.0722 & 0.0478 & 0.1303 & 0.1321 & 0.0559 \\
\hline 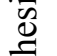 & & $(2.88)$ & $(4.05)$ & $(3.35)$ & $(4.25)$ & $(3.42)$ & $(3.92)$ \\
\hline 宽 & Volatility & 0.0239 & 0.0009 & 0.0107 & 0.0195 & -0.0224 & 0.0169 \\
\hline 空 & & $(5.06)$ & $(0.14)$ & $(2.58)$ & $(2.54)$ & $(-2.83)$ & (3.94) \\
\hline & BeforeEarnAnnounce & 0.0239 & 0.0046 & 0.0275 & 0.0000 & 0.0054 & 0.0251 \\
\hline & & $(3.17)$ & $(0.71)$ & (4.14) & $(0.01)$ & $(0.69)$ & $(3.99)$ \\
\hline & AfterEarnAnnounce & 0.0226 & 0.0069 & 0.0128 & 0.0143 & 0.0140 & 0.0124 \\
\hline & & $(6.51)$ & $(2.14)$ & $(3.74)$ & (4.39) & $(3.91)$ & (3.89) \\
\hline & InfoComp*QuotSpread & 0.6039 & 0.8374 & 0.5157 & 1.3100 & 0.6104 & 1.1258 \\
\hline$n$ & & $(6.14)$ & $(8.69)$ & $(6.98)$ & $(4.59)$ & $(6.24)$ & $(9.95)$ \\
\hline$\dot{I}$ & (1-InfoComp)*QuotSpread & 0.5806 & 2.1102 & 0.8571 & 7.0244 & 1.4534 & 0.8795 \\
\hline & & $(4.37)$ & $(8.02)$ & $(6.94)$ & $(4.85)$ & $(5.33)$ & $(6.61)$ \\
\hline & ShortSide & 0.0147 & 0.0089 & 0.0132 & 0.0094 & 0.0154 & 0.0091 \\
\hline 6 & & $(4.22)$ & $(2.75)$ & $(4.02)$ & $(2.74)$ & (4.17) & $(2.92)$ \\
\hline$\dot{I}$ & MultipleInsiders & 0.0928 & 0.0171 & 0.0519 & 0.0530 & 0.0545 & 0.0498 \\
\hline & & $(30.64)$ & $(6.33)$ & $(17.79)$ & (19.03) & $(17.54)$ & $(18.46)$ \\
\hline & LogMarketCap & 0.0551 & 0.0496 & 0.0532 & 0.0566 & 0.0457 & 0.0535 \\
\hline & & $(44.60)$ & (41.79) & (35.92) & $(44.53)$ & $(35.22)$ & $(41.30)$ \\
\hline & SOX & & & -0.0248 & -0.0607 & -0.0029 & -0.0823 \\
\hline & & & & $(-2.45)$ & $(-5.50)$ & $(-0.26)$ & $(-8.15)$ \\
\hline & Observations & 140,210 & 167,280 & 148,847 & 158,643 & 132,489 & 170,253 \\
\hline & Pseudo $\mathrm{R}^{2}$ & 0.188 & 0.127 & 0.159 & 0.144 & 0.154 & 0.153 \\
\hline & Year dummies & Yes & Yes & Yes & Yes & Yes & Yes \\
\hline & Industry dummies & Yes & Yes & Yes & Yes & Yes & Yes \\
\hline
\end{tabular}




\section{Table 9: The impact of Sarbanes-Oxley on trading behavior}

This table presents results for time series regressions with the aggregated Volume of stealth trading transactions (StealthVolume), the proportion of stealth trades of all insider transactions measured by Volume (StealthProportion), the time span between single stealth trades in days (TimeSpan) and the reporting delay of insider transactions in days (Delay) as dependent variables. Trend is a variable that equals zero for January 1996 and increases by one for each month after that. All models include CEO, Officer, Chairman, OtherInsider, Purchase, AQLoading, R\&D, Volatility, BeforeEarnAnnounce, AfterEarnAnnounce, StakeDecile, EffectiveSpread, ShortSide, MultipleInsiders, and LogMarketCap as control variables. See Table 2 for a definition of all variables. All variables are measured as monthly averages. For each reported independent variable, the table displays the slope estimate and, in parentheses, the t-statistic of the two-sided test for zero slope based on Newey-West heteroscedasticityrobust standard errors, which also allow for autocorrelation of one lag.

\section{Panel A}

\begin{tabular}{lcccc}
\hline & StealthVolume & $\begin{array}{c}\text { Stealth } \\
\text { Proportion }\end{array}$ & TimeSpan & Delay \\
\hline LagDepVar & $\mathbf{( 1 )}$ & $\mathbf{( 2 )}$ & $\mathbf{( 3 )}$ & $\mathbf{( 4 )}$ \\
\multirow{2}{*}{ SOX } & -0.0167 & -0.1855 & 0.2187 & 0.4664 \\
& $(-0.25)$ & $(-1.81)$ & $(2.22)$ & $(5.94)$ \\
Trend & -474.3171 & -0.1381 & -0.8827 & -20.2239 \\
& $(-1.46)$ & $(-5.32)$ & $(-7.57)$ & $(-7.84)$ \\
& -8.4714 & 0.0013 & -0.0075 & 0.0440 \\
Observations & $(-2.25)$ & $(3.29)$ & $(-3.55)$ & $(1.35)$ \\
\hline Controls & 131 & 131 & 131 & 131 \\
Year dummies & Yes & Yes & Yes & Yes \\
\hline
\end{tabular}

\section{Panel B}

\begin{tabular}{lcccc}
\hline & StealthVolume & $\begin{array}{c}\text { Stealth } \\
\text { Proportion }\end{array}$ & TimeSpan & Delay \\
\hline LagDepVar & $\mathbf{( 1 )}$ & $\mathbf{( 2 )}$ & $\mathbf{( 3 )}$ & $\mathbf{( 4 )}$ \\
& -0.1405 & -0.2181 & -0.0161 & 0.2217 \\
SOX & $(-2.07)$ & $(-2.21)$ & $(-0.15)$ & $(2.67)$ \\
& $-1,270.3730$ & -0.1692 & -1.0950 & -21.6098 \\
\hline Observations & $(-2.03)$ & $(-3.90)$ & $(-6.65)$ & $(-7.21)$ \\
\hline Controls & 131 & 131 & 131 & 131 \\
Year dummies & Yes & Yes & Yes & Yes \\
\hline
\end{tabular}




\section{Table 10: Robustness checks}

The table presents results for Probit regressions with Stealth as dependent variable. Model (1) uses an alternative definition of Stealth as dependent variable, here a stealth trading sequence can only last for 7 days, however the disclosure of a prior trade within a period of 7 days does not terminate the sequence. Model (2) includes AbnormalAccruals from the Jones (1991) model as measure for opaqueness. Models (3) to (7) use different measures of liquidity, the header of the table reports the measure used for each column. Coefficients for each of the liquidity measures are reported in the line LiquidityMeasure. See Table 2 for a definition of all variables. For each independent variable, the table displays the marginal effects (evaluated at the mean of the independent variables) and, in parentheses, the t-statistic of the two-sided t-test for a coefficient equal to zero. In all regressions $t$-values are based on heteroscedasticity-robust standard errors. We also report McFadden's R². 


\begin{tabular}{|c|c|c|c|c|c|c|c|}
\hline & $\begin{array}{l}\text { Stealth } \\
\text { (7 days) }\end{array}$ & $\begin{array}{l}\text { Jones } \\
\text { model }\end{array}$ & Amihud & LOT & $\begin{array}{c}\text { Price } \\
\text { Impact }\end{array}$ & Turnover & Lambda \\
\hline & (1) & (2) & (3) & (4) & (5) & (6) & (7) \\
\hline$\rightarrow$ StakeDecile & 0.0936 & 0.0911 & 0.0872 & 0.0872 & 0.0873 & 0.0879 & 0.0887 \\
\hline$\dot{I}$ & $(215.02)$ & $(157.40)$ & (191.82) & $(191.56)$ & (191.68) & (180.83) & (152.99) \\
\hline $\mathrm{CEO}$ & 0.0090 & 0.0029 & 0.0163 & 0.0161 & 0.0162 & 0.0157 & 0.0171 \\
\hline is Officer & $\begin{array}{l}(2.70) \\
-0.0051\end{array}$ & $\begin{array}{c}(0.07) \\
-0.0248\end{array}$ & $\begin{array}{c}(4.08) \\
-0.0125\end{array}$ & $\begin{array}{c}(4.02) \\
-0.0128\end{array}$ & $\begin{array}{c}(4.05) \\
-0.0124\end{array}$ & $\begin{array}{c}(4.52) \\
-0.0127\end{array}$ & $\begin{array}{c}(3.87) \\
-0.0199\end{array}$ \\
\hline $\bar{\theta}$ & $(-2.29)$ & $(-8.21)$ & $(-5.27)$ & $(-5.39)$ & $(-5.24)$ & $(-5.36)$ & $(-6.57)$ \\
\hline 들 Chairman & 0.0048 & -0.0115 & 0.0085 & 0.0075 & 0.0086 & 0.0079 & 0.0118 \\
\hline 总 & $(0.80)$ & $(-1.45)$ & $(1.34)$ & $(1.18)$ & $(1.35)$ & $(1.24)$ & $(1.49)$ \\
\hline OtherInsider & 0.0802 & 0.0686 & 0.0767 & 0.0760 & 0.0766 & 0.0773 & 0.0767 \\
\hline & (21.22) & (13.64) & $(18.89)$ & (18.67) & (18.84) & $(19.04)$ & $(15.40)$ \\
\hline$m$ Purchase & 0.0071 & 0.0103 & 0.0198 & 0.0182 & 0.0201 & 0.0191 & 0.0222 \\
\hline \pm & $(2.83)$ & $(2.99)$ & $(7.46)$ & $(6.82)$ & $(7.56)$ & (7.18) & (6.54) \\
\hline AQLoading & 0.0037 & & 0.0022 & 0.0016 & 0.0024 & 0.0029 & 0.0023 \\
\hline & $(3.81)$ & & $(2.36)$ & $(1.70)$ & $(2.61)$ & (3.10) & (1.94) \\
\hline AbnormalAccruals & & $\begin{array}{c}-0.01037 \\
(-0.63)\end{array}$ & & & & & \\
\hline InformationComponent & & & 0.0106 & 0.0111 & 0.0109 & 0.0076 & -0.0103 \\
\hline & & & $(2.62)$ & $(2.75)$ & $(2.70)$ & $(1.85)$ & $(-1.89)$ \\
\hline 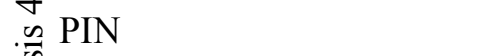 & 0.0190 & -0.0154 & 0.0067 & 0.0019 & 0.0046 & 0.0014 & 0.0371 \\
\hline Q & $(1.55)$ & $(-0.86)$ & $(0.50)$ & $(0.15)$ & $(0.34)$ & $(0.11)$ & $(2.22)$ \\
\hline R\&D & 0.0896 & 0.0469 & 0.0599 & 0.0544 & 0.0596 & 0.0594 & 0.0534 \\
\hline & $(7.26)$ & $(2.90)$ & $(4.68)$ & $(4.22)$ & $(4.65)$ & $(4.65)$ & $(3.22)$ \\
\hline Volatility & 0.0201 & 0.0170 & 0.0206 & 0.0116 & 0.0217 & 0.0308 & 0.0210 \\
\hline & $(6.02)$ & (3.87) & $(5.60)$ & $(3.04)$ & $(6.03)$ & $(7.40)$ & $(4.63)$ \\
\hline BeforeEarnAnnounce & -0.0044 & 0.0154 & 0.0159 & 0.0159 & 0.0160 & 0.0172 & 0.0093 \\
\hline & $(-0.96)$ & $(2.44)$ & $(3.28)$ & $(3.26)$ & $(3.29)$ & $(3.54)$ & $(1.52)$ \\
\hline AfterEarnAnnounce & 0.0169 & 0.0166 & 0.0133 & 0.0134 & 0.0135 & 0.0135 & 0.0075 \\
\hline & $(7.5)$ & $(5.6)$ & $(5.7)$ & $(5.7)$ & $(5.7)$ & $(5.8)$ & $(2.5)$ \\
\hline InfoComp*QuotSpread & 0.8144 & 0.6846 & & & & & \\
\hline & $(15.67)$ & $(8.36)$ & & & & & \\
\hline$\cong(1$-InfoComp)*QuotSpread & 0.8157 & 0.9904 & & & & & \\
\hline क्ष & $(15.67)$ & $(7.03)$ & & & & & \\
\hline 홍 LiquidityMeasure & & & 0.0007 & 0.5283 & 0.0014 & -0.5249 & 0.0349 \\
\hline & & & $(2.17)$ & $(8.34)$ & $(0.78)$ & $(-3.99)$ & $(5.46)$ \\
\hline Gamma & & & & & & & 0.1630 \\
\hline & & & & & & & $(12.04)$ \\
\hline ShortSide & 0.0164 & 0.0109 & 0.0519 & 0.0526 & 0.0520 & 0.0544 & 0.0670 \\
\hline 6 & $(7.34)$ & $(3.60)$ & $(25.94)$ & $(26.24)$ & (25.96) & $(25.78)$ & $(26.35)$ \\
\hline MultipleInsiders & 0.0398 & 0.0535 & 0.0120 & 0.0116 & 0.01218 & 0.0113 & 0.0155 \\
\hline & $(20.92)$ & $(21.04)$ & $(5.07)$ & $(4.92)$ & $(5.16)$ & $(4.80)$ & $(5.13)$ \\
\hline LogMarketCap & 0.0566 & 0.0507 & 0.0461 & 0.0484 & 0.0457 & 0.0463 & 0.0423 \\
\hline & $(72.29)$ & $(47.31)$ & $(59.46)$ & $(57.68)$ & $(59.59)$ & $(59.20)$ & $(43.65)$ \\
\hline SOX & -0.0120 & -0.0285 & -0.0366 & -0.0339 & -0.0372 & -0.0363 & -0.0671 \\
\hline & $(-1.74)$ & $(-3.27)$ & $(-4.98)$ & $(-4.59)$ & $(-5.03)$ & $(-4.93)$ & $(-7.09)$ \\
\hline Observations & 347,351 & 193,170 & 307,546 & 306,617 & 306,815 & 307,546 & 179,242 \\
\hline Pseudo R ${ }^{2}$ & 0.164 & 0.158 & 0.148 & 0.148 & 0.148 & 0.149 & 0.178 \\
\hline Year and industry dummies & Yes & Yes & Yes & Yes & Yes & Yes & Yes \\
\hline
\end{tabular}




\section{Table 11: Abnormal disclosure day returns and stealth trading}

The table presents results for OLS regressions with abnormal disclosure day returns as dependent variable. The 1-day event window is the disclosure date of the first transaction of a series of stealth trades or the disclosure date of a non-stealth trade. See Table 2 for a definition of all variables. For each independent variable, the table displays the slope estimate and, in parentheses, the p-value of the two-sided t-test for zero slope. In all OLS regressions t-statistics are based on heteroscedasticity-robust standard errors. 


\begin{tabular}{|c|c|c|c|c|c|c|c|c|}
\hline & \multirow{2}{*}{\multicolumn{2}{|c|}{ Purchases }} & \multicolumn{2}{|c|}{ Sales } & \multirow{2}{*}{\multicolumn{4}{|c|}{$\begin{array}{cc}\text { Purchases } & \text { Sales } \\
\text { OLS (Winsorized } 1 \%)\end{array}$}} \\
\hline & & & \multicolumn{2}{|c|}{ OLS } & & & & \\
\hline & (1) & (2) & (3) & (4) & (5) & (6) & (7) & (8) \\
\hline Stealth & $\begin{array}{r}0.0007 \\
(2.72)\end{array}$ & $\begin{array}{c}-0.0014 \\
(-4.23)\end{array}$ & $\begin{array}{c}0.0000 \\
(0.07)\end{array}$ & $\begin{array}{l}0.0004 \\
(2.71)\end{array}$ & $\begin{array}{c}0.0006 \\
(2.74)\end{array}$ & $\begin{array}{r}-0.0011 \\
(-3.91)\end{array}$ & $\begin{array}{l}-0.0002 \\
(-1.59)\end{array}$ & $\begin{array}{c}0.0003 \\
(2.47)\end{array}$ \\
\hline StakeDecile & & $\begin{array}{c}0.0006 \\
(8.5)\end{array}$ & & $\begin{array}{c}0.0000 \\
(0.1)\end{array}$ & & $\begin{array}{c}0.0005 \\
(8.3) \\
\end{array}$ & & $\begin{array}{c}0.0000 \\
(1.4)\end{array}$ \\
\hline$\overline{\mathrm{CEO}}$ & & $\begin{array}{c}0.0001 \\
(0.15)\end{array}$ & & $\begin{array}{c}0.0004 \\
(1.74)\end{array}$ & & $\begin{array}{c}0.0002 \\
(0.37)\end{array}$ & & $\begin{array}{c}0.0004 \\
(1.73)\end{array}$ \\
\hline Officer & & $\begin{array}{c}0.0005 \\
(1.63)\end{array}$ & & $\begin{array}{c}0.0002 \\
(0.96)\end{array}$ & & $\begin{array}{c}0.0006 \\
(1.95)\end{array}$ & & $\begin{array}{c}0.0002 \\
(1.74)\end{array}$ \\
\hline Chairman & & $\begin{array}{c}0.0010 \\
(0.92)\end{array}$ & & $\begin{array}{c}0.0002 \\
(0.46)\end{array}$ & & $\begin{array}{c}0.0012 \\
(1.29)\end{array}$ & & $\begin{array}{r}0.0001 \\
(0.36)\end{array}$ \\
\hline OtherInsider & & $\begin{array}{c}-0.0013 \\
(-2.26)\end{array}$ & & $\begin{array}{r}-0.0007 \\
(-2.01)\end{array}$ & & $\begin{array}{r}-0.0011 \\
(-2.14)\end{array}$ & & $\begin{array}{r}-0.0007 \\
(-2.63)\end{array}$ \\
\hline AQLoading & & $\begin{array}{c}0.0006 \\
(3.67)\end{array}$ & & $\begin{array}{c}-0.0001 \\
(-1.46)\end{array}$ & & $\begin{array}{r}0.0005 \\
(3.79)\end{array}$ & & $\begin{array}{c}-0.0002 \\
(-2.25)\end{array}$ \\
\hline InformationComponent & & $\begin{array}{c}0.0004 \\
(0.64)\end{array}$ & & $\begin{array}{c}-0.0001 \\
(-0.25)\end{array}$ & & $\begin{array}{c}0.0003 \\
(0.50)\end{array}$ & & $\begin{array}{l}0.0000 \\
(-0.06)\end{array}$ \\
\hline PIN & & $\begin{array}{c}-0.0036 \\
(-2.10)\end{array}$ & & $\begin{array}{c}-0.0046 \\
(-3.80)\end{array}$ & & $\begin{array}{c}-0.0033 \\
(-2.41)\end{array}$ & & $\begin{array}{c}-0.0040 \\
(-4.13)\end{array}$ \\
\hline $\mathrm{R} \& \mathrm{D}$ & & $\begin{array}{c}0.0062 \\
(2.04)\end{array}$ & & $\begin{array}{c}-0.0014 \\
(-0.70)\end{array}$ & & $\begin{array}{c}0.0032 \\
(1.46)\end{array}$ & & $\begin{array}{c}-0.0022 \\
(-1.88)\end{array}$ \\
\hline Volatility & & $\begin{array}{c}0.0024 \\
(2.78)\end{array}$ & & $\begin{array}{c}-0.0011 \\
(-1.55)\end{array}$ & & $\begin{array}{c}0.0013 \\
(2.00)\end{array}$ & & $\begin{array}{c}-0.0021 \\
(-5.69)\end{array}$ \\
\hline BeforeEarnAnnounce & & $\begin{array}{c}0.0008 \\
(1.45)\end{array}$ & & $\begin{array}{l}0.0009 \\
(2.36)\end{array}$ & & $\begin{array}{c}0.0007 \\
(1.39)\end{array}$ & & $\begin{array}{c}0.0010 \\
(3.15)\end{array}$ \\
\hline AfterEarnAnnounce & & $\begin{array}{c}0.0001 \\
(0.23) \\
\end{array}$ & & $\begin{array}{c}-0.0002 \\
(-1.31) \\
\end{array}$ & & $\begin{array}{c}0.0002 \\
(0.57) \\
\end{array}$ & & $\begin{array}{r}-0.0003 \\
(-1.94) \\
\end{array}$ \\
\hline EffectiveSpread & & $\begin{array}{c}0.0203 \\
(1.13) \\
\end{array}$ & & $\begin{array}{c}0.0506 \\
(2.76) \\
\end{array}$ & & $\begin{array}{c}-0.0008 \\
(-0.06)\end{array}$ & & $\begin{array}{r}0.0313 \\
(2.82) \\
\end{array}$ \\
\hline MultipleInsiders & & $\begin{array}{c}0.0013 \\
(4.33)\end{array}$ & & $\begin{array}{c}-0.0003 \\
(-2.48)\end{array}$ & & $\begin{array}{c}0.0011 \\
(4.32)\end{array}$ & & $\begin{array}{c}-0.0004 \\
(-3.46)\end{array}$ \\
\hline ShortSide & & $\begin{array}{c}-0.0002 \\
(-0.59) \\
\end{array}$ & & $\begin{array}{c}-0.0009 \\
(-5.16)\end{array}$ & & $\begin{array}{c}-0.0002 \\
(-0.77) \\
\end{array}$ & & $\begin{array}{c}-0.0008 \\
(-5.20) \\
\end{array}$ \\
\hline LogMarketCap & & $\begin{array}{c}-0.0003 \\
(-2.18)\end{array}$ & & $\begin{array}{c}-0.0001 \\
(-0.87)\end{array}$ & & $\begin{array}{c}-0.0003 \\
(-3.00)\end{array}$ & & $\begin{array}{l}0.0000 \\
(-0.56)\end{array}$ \\
\hline SOX & & $\begin{array}{c}0.0052 \\
(4.63) \\
\end{array}$ & & $\begin{array}{c}0.0009 \\
(1.65) \\
\end{array}$ & & $\begin{array}{r}0.0047 \\
(4.85) \\
\end{array}$ & & $\begin{array}{r}0.0008 \\
(1.66) \\
\end{array}$ \\
\hline Observations & 147,380 & 86,009 & 325,679 & 221,561 & 147,380 & 86,009 & 325,679 & 221,561 \\
\hline Adjusted $\mathrm{R}^{2}$ & 0.000 & 0.013 & 0.000 & 0.003 & 0.000 & 0.013 & 0.000 & 0.004 \\
\hline Year dummies & No & Yes & No & Yes & No & Yes & No & Yes \\
\hline Industry dummies & No & Yes & No & Yes & No & Yes & No & Yes \\
\hline
\end{tabular}




\section{Figure 1: Development of stealth trading over time \\ Panel A: Proportion of stealth trades}

The figure displays the development of the proportion of stealth trades of all insider transactions over the sample period. The dashed vertical line marks the month when the Sarbanes-Oxley act came into force (August 2002).

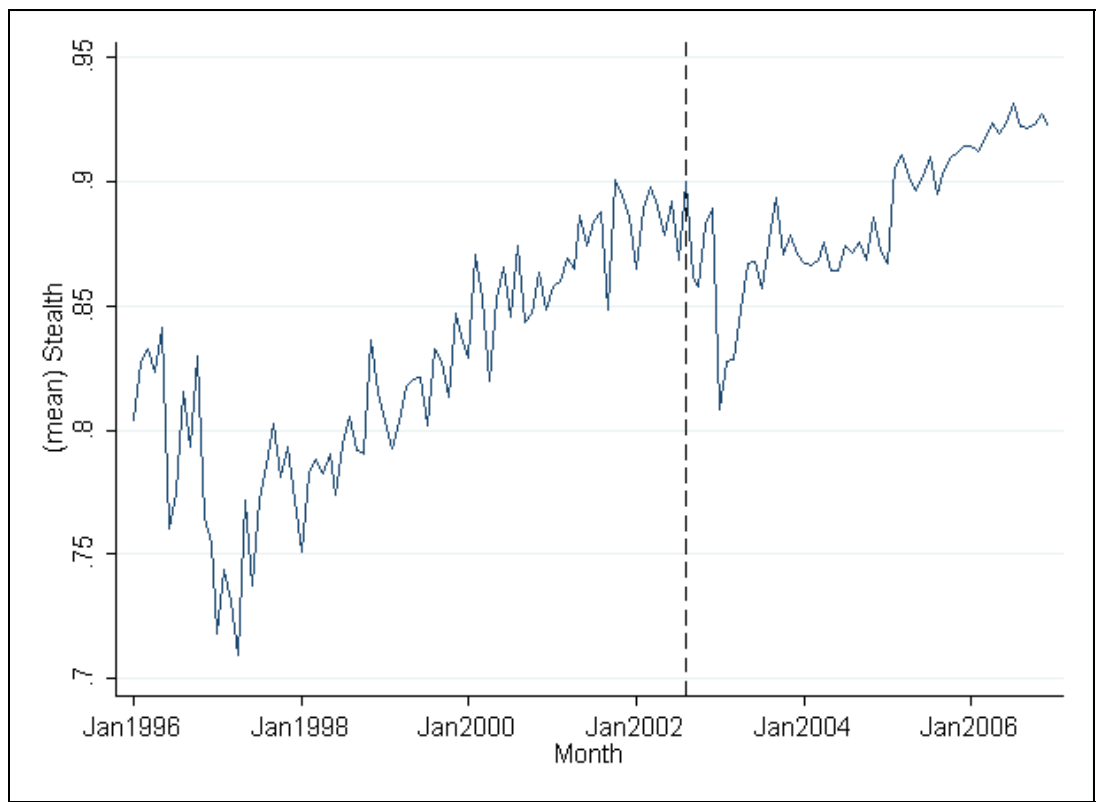

\section{Panel B: Number of transactions in a stealth trading sequence}

The figure displays the development of the average number of transactions in a stealth trading sequence over the sample period. The dashed vertical line marks the month when the Sarbanes-Oxley act came into force (August 2002).

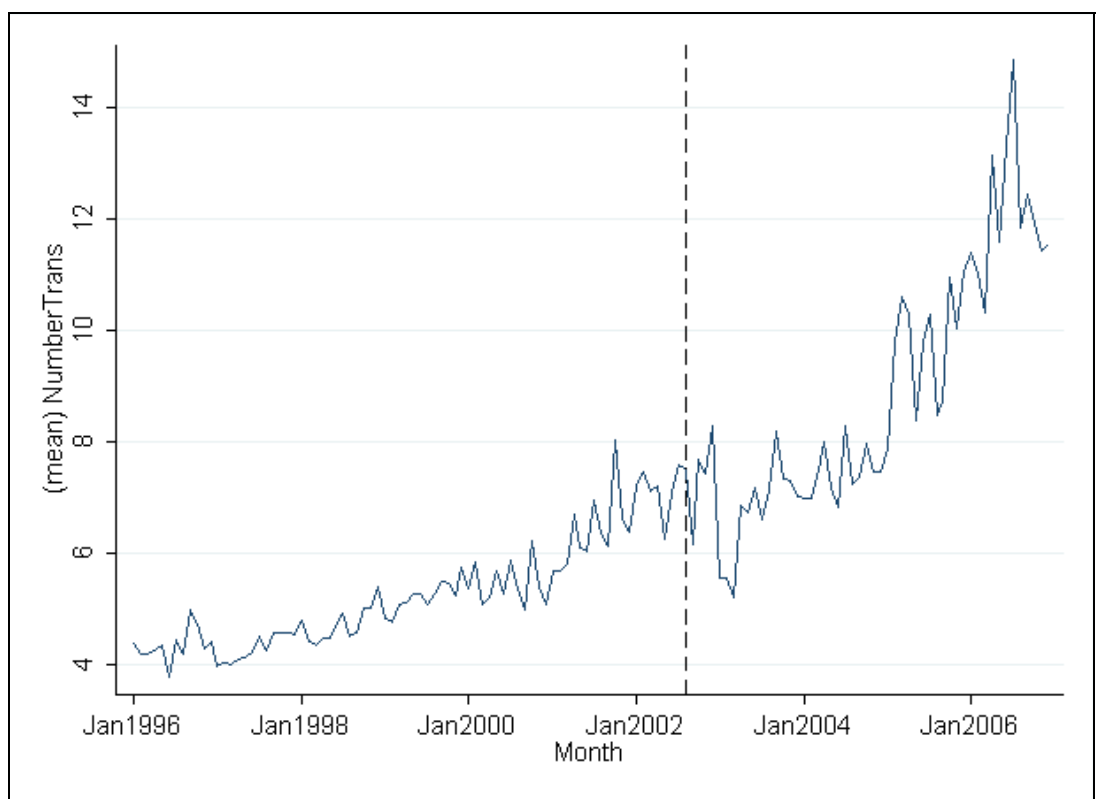

